\title{
Improving the cooling performance of a data center: impact of unit arrangement and CFD setups
}

\author{
S. Nassar*, A. Abdelsamie, A.Mohamed, M. Sedrak \\ Department of Mechanical Power Engineering, Faculty of Engineering at El-Mattaria, \\ Helwan University, Masaken El-Helmia P.O., Cairo 11718, Egypt.
}

\section{KEYWORDS}

Data centers, Energy saving, Cooling performance

\begin{abstract}
Data center can be considered as the heart of any large institution; it uses for a lot of purposes such as data transfer, data storage, data analysis, etc. The performed operations release huge amount of heat, which should be cooled down. Therefore, a huge amount of energy is required for this cooling process. This work aims to improve the cooling efficiency and consequently, decrease the energy consumption, which is required for a specific data center. The improvements have been achieved by introducing two modifications: modifying the locations of heat sources (hereinafter will refer as racks units) and cooling machines (hereinafter will refer to CRACS units), and the airflow distribution path; where the suggested arrangement is different than the standard one, and changing the location of the server fan compared to the standard one. As a first step, the quality of the numerical simulation of the suggested modifications should be evaluated. This assessment was done by testing the impact of the mesh size on the air velocity and temperature as the main parameters in the current analysis. CFD Numerical investigation is done using ANSYS 16. The geometry is created using AUTOCAD 18, then it is exported to ANSYS. The meshing is created using ANSYS workbench with taken into account several mesh refinement. It was found that the suggested modifications increase the cooling performance and reduces energy consumption.
\end{abstract}

*Corresponding author. Tel.: +201000537865. Email addresses: nassargroupp@ gmail.com, (Said Nassar). 
Momtaz Sedrak / Engineering Research Journal 168 (Decamber2020) M1- M29

Nomenclature

$\begin{array}{ll}C p & \text { Specific heat capacity at constant pressure }(\mathrm{J} / \mathrm{Kg} . \mathrm{k}) \\ \text { CRAC } & \text { Computer Room Air Conditioning } \\ \text { DCs } & \text { Data centres } \\ \dot{m} & \text { Mass flow rate }(\mathrm{kg} / \mathrm{s}) \\ Q & \text { Total power dissipation from data center components }(\mathrm{W}) \\ T & \text { Temperature }\left({ }^{\circ} \mathrm{C} / \mathrm{K}\right) \\ T_{\text {ref }} & \text { Reference temperature }\left({ }^{\circ} \mathrm{C} / \mathrm{K}\right) \\ \text { TWh } & \text { Terra Watt.hour } \\ U & \text { Velocity }(\mathrm{m} / \mathrm{s})\end{array}$

\section{Superscript}

$\mathrm{C}$

$\mathrm{R}$

\section{Subscripts}

In

max-all

min-rec

min-all

out

Ref

Return

Supply

\section{Abbreviations}

RHI

Return heat index

RCI

RTI

SHI

\section{CRAC}

rack
Maximum allowable

Minimum allowable

Outlet

CRAC supply

Return air

Supply air

Minimum recommended 


\section{1-Introduction}

The amount of energy consumed by data centers (DCs), all over the world, about 198 TWh which is about $1 \%$ of global final demand for electricity as it was reported by international energy agency 2018 [1], whereas the power, which is needed for the cooling process, represents about 50\% of the power consumption of data center equipment.

A typical data center with a raised floor air supplying system can be represented by Fig. (1). Most of the standard DCs are similar in terms of layout and features, and they are following the raised-floor concept. The racks are arranged on the raised floor in a hotand cold-aisle configuration. The cold-aisle contains perforated tiles that supply cold air to the inlets of the server racks from the under-floor plenum. The hot air leaving the racks is collected by the computer room air conditioning unit (CRAC), which then supplies cold air to the plenum to complete the cycle. This concept prevents unwanted mixing of the hot air expelled from the servers with the cooling air coming from the perforated tiles, but recirculation is unavoidable in some cases (i.e. the racks at the ends of a row and the topmost servers).

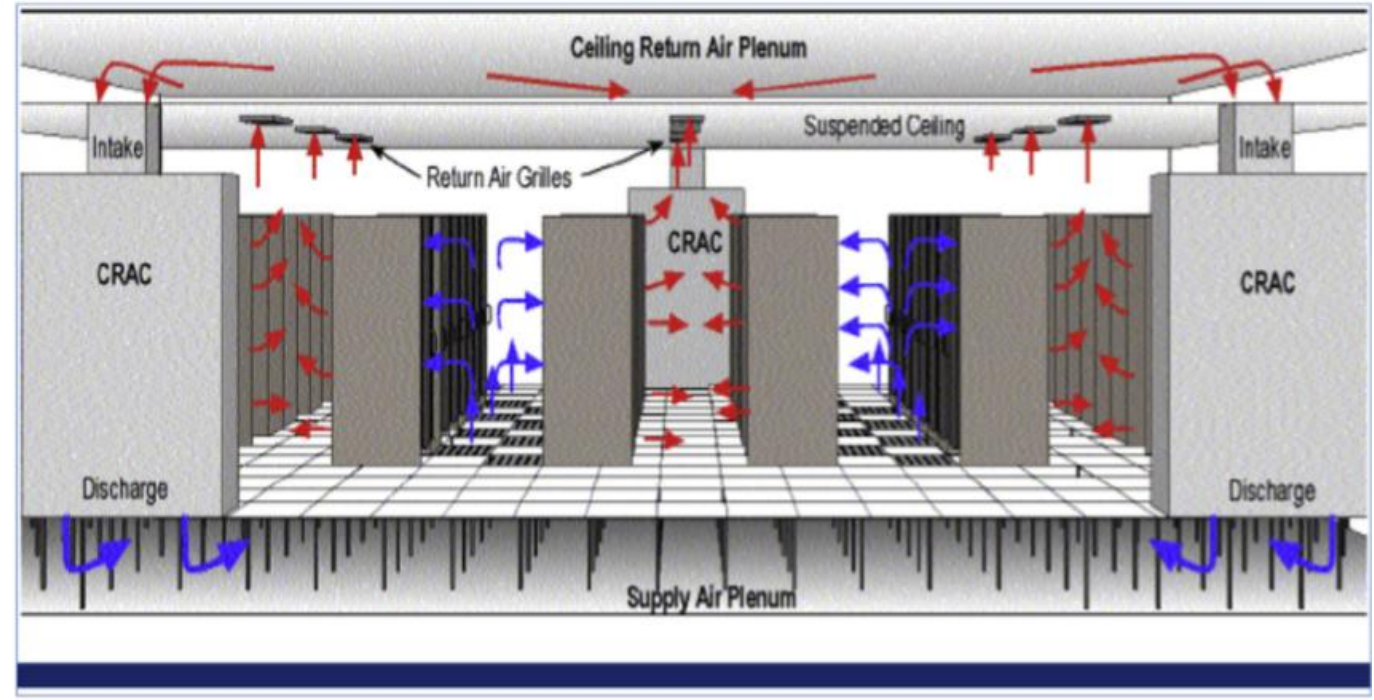

Fig. 1 Example of a typical data center with the raised-floor concept [2]

A lot of literature investigated the cooling performance in the data center; here some of them were reviewed. Nada and Elfeky [3] studied the effect of using containments in cold aisles and their effects on the thermal efficiencies using experiments done on a scaled model with side containments or side and top containments or with no containments and it was concluded that the temperature distribution is enhanced and the 
hot air recirculation and cold air bypass are mostly diminished and thermal efficiency is increased using both sides containments and side and top containments; they also observed an increase in the power density improves the supply heat index but results in hotter servers and the data center containments enhancements are more significant with increasing the power density which is the metric that usually refers to the power draw of a single, fully populated server rack, as measured in kilowatts.Lyu et al. [4] analyzed the enclosure effect on a small scale data center using CFD to find the temperature and velocity distribution over multiple sections with different orientations over four different configurations: (1) fully open, (2) semi-enclosed cold aisle, (3) fully enclosed hot aisle, and (4) fully enclosed hot aisle. It was found that the fully open configuration had air leakage problems (mixing of cold and hot air); whereas that the fully enclosed hot and cold aisle had significant improvement over the cooling system along with the semi-enclosed. The enclosed cold aisle had fire safety problems; the enclosed hot aisle had cooler temperatures and they were more costly. Therefore, the semi-closed cold aisle was the recommended configuration.

Faisal and Isaac [5] studied the pressure, temperature, and air velocity distribution over the data center. The data center room dimensions are $4 \times 3 \times 4 \mathrm{~m}^{3}$ and the geometry was meshed using CATIA with triangular mesh and a different number of meshes, then imported to ANSYS to analyze these parameters at a constant height of $2 \mathrm{~m}$. It was concluded that the optimum pressure distribution and temperature ranges within ASHRAE limitations were only found in the bottom supply and ceiling exhaust configuration. Schmidt et al. [6] studied CRACS airflow directions and distribution with various configurations of perforated tile arrays (rows and columns) with constant height of raised floor and it was concluded that : (1) An improved airflow distribution is achieved when both CRAC units discharge air in the same direction, (2) the airflow distribution is more nonuniform when the CRAC units are oriented such that they discharge in opposing direction and their airstreams collide, and (3) there is reverse flow (flow into the plenum) through the perforated tiles close to the CRAC units in operation; the extend of reverse flow diminishes as the number of perforated tiles is reduced. Yang et al. [7] studied the effect of free cooling on energy saving in the data center. The test was performed in the city of Jinan (China), and it was found that the average temperature during January, February, and December was below $1 \mathrm{deg}$. Celsius in which the data center can be cooled by free cooling using dry cooler due to the low temperature of the outside air. On the other side, it was found that the average temperature during March, April, October, and November is below $15^{\circ} \mathrm{C}$ in which the water is cooled to $15^{\circ} \mathrm{C}$ which reduces the load of the chiller; and part of the 
compressor is shut, which saves energy significantly and this system can meet the criteria of multiple locations. In the work of Shrivastava et al.[8], seven different configurations of CARC units are studied along with one special case of the sealed cold aisle; they found that the room supply/ceiling return to be the most effective of the seven cases and that the special case had the best performance but comes with many assumptions and it's difficult to implement . Karki et al. [9] studied different types of techniques that can be used for controlling airflow distribution. These techniques involve changing the plenum height and opening area of the perforated tiles. Also, they installed thin (solid and perforated) partitions in the plenum; these thin partitions offer significant flexibility for controlling the airflow distribution, especially in existing data centers.

In the work of Bhopte et al. [10], cold aisle, ceiling height, and plenum height are all studied to minimize rack inlet air temperature using CFD analysis over a single variable baseline model, then two and three variable design optimization which proved to have significant improvement over the baseline model. VanGlider et al. [11] studied ten-floor plans: one is a hypothetical layout, and nine are based on actual data centers. Multiple recommendations were concluded from this study including the following: (1) Use only the more-restrictive perforated tiles (e.g. 25\% opening from perforated tiles) for general deployment, (2) high-flow perforated tiles (e.g. 56\% open) should be used only in special circumstances, (3) create standard hot- and cold-aisle layouts utilizing rectangular, symmetric layouts, (4) locate CRACs at the end of the hot-aisle (far from perforated tiles) and avoid rows longer than about 20 perforated tiles, (5) design plenums for clear airflow with height of $0.61 \mathrm{~m}$ or more, (6) minimize leakage airflow through non-perforated tile openings in the raised floor, (7) keep chilled water pipes and cables away from the exhaust regions of $\mathrm{A} / \mathrm{C}$ units, and (8) do not increase the airflow rate without addressing the other factors listed above. Huang et al. [12] investigated the flow patterns of three air supply setups: (1) underfloor cooling system, (2) row level cooling system, and (3) rack-level cooling system. Numerical simulations were used in this study by considering multiple indices for airflow and temperature. It was found that the rack level cooling system had the best performance among them, however, it consumes more power. Ling et al. [13] examined the effect of using lake water source to cool the data center under three different modes: (1) free cooling, (2) partial free cooling, and (3) using chillers only. The first two modes showed significant improvement in efficiency and power saving. Dong et al. [14] studied the use of indirect cooling of an open cooling tower and it is found that the COP increased. Cho et al. [15] investigated the air distribution of high-density data center with 12 different cases with 
the combination of (1) fully or locally ducted, (2) CRAC flooded with underfloor supply, overhead supply, or return. It was found that local ducted overhead supply and return was the most suitable technique, with the lower sections of the server having higher temperatures. On the other side, the underfloor system showed better performance regarding air recirculation with better overall COPs. Additionally, the flooded systems found to be more suitable for small datacenters. Fernando et al. [16] studied the impact of scaling down the data center prototype on the temperature and air flow distribution over the data center using the ANSYS software the temperature on 40 points in each model on one full scaled prototype and two half scaled models using both Archimedes and Reynolds number equivalence with $3.7 \%$ and $14.7 \%$ temperature error margins respectively and the airflow patterns weren't accurate. Jin et al. [17] investigated the airflow distribution with changing different parameters: (1) Inclined partition containment, (2) perforated tiles with porosity ratio 25\%, (3) plenum height, and (4) CRAC and racks arrangements. They found the optimum air distribution with each of these parameters when the CRAC is located at the end of each row of the racks and plenum height between 0.79-0.91 optimum distribution is achieved. Nada et al, [18] studied different configurations of CRAC units and physical separations of cold and hot aisles. In this work, measurable performance indices have been used: (1) supply/return heat index (SHI/RHI), (2) return temperature index (RTI), (3) and return cooling index (RCI), to measure the thermal management effectiveness of data center racks. It was found that the measurable performance parameters of a rack is strongly depending on the rack location in the racks array. Furthermore, it was observed that using cold aisle containments in the different CRACs layouts decreases the recirculation and bypass of air flow around the first, middle and last racks in a rack row. At the end they found that the roof top containment is more effective in thermal management enhancement as compared to side containment.

In the current work, novel arrangements have been introduced by applying two modifications: (1) modifying the locations of heat sources (hereinafter will refer as racks units) and cooling machines (hereinafter will refer to CRACS units), and the airflow distribution path; where the suggested arrangement is different than the standard one, and (2) changing the location of the server fan compared to the standard one. The quality of the numerical simulation of the suggested modifications will be evaluated as well.

This manuscript is arranged as follows; geometry and components arrangements are discussed in Sec. 2. In Sec. 3, the mathematical formulation and numerical techniques are reviewed. The results are presented in Sec. 4 before concluding in Sec. 5. 


\section{GEOMETRY AND COMPONENTS ARRANGEMENTS}

In the traditional data center, the airflow pattern and temperature distribution can be illustrated by Figs. (1) and (2)a. In these figures, almost the racks are located on the raised floor in a hot-/cold-aisle arrangement. The cold aisle contains perforated tiles that supply cold air to the inlets of the server racks from the under-floor plenum. The hot air leaving the racks from the back and collected by the CRAC units, which then supply the cold air to the plenum to complete the cycle. This way the mixing between the hot air expelled from the racks and the cooling air coming from the perforated tiles will be prevented. In the current work, the tiles opening is located exactly under each rack; the air enters inside the rack and leaves from the top of the racks as showed in Fig. (2)b. The impact of the suggested changes on the velocity, temperature, and cooling performance will be discussed in details in the next sections.

(a)

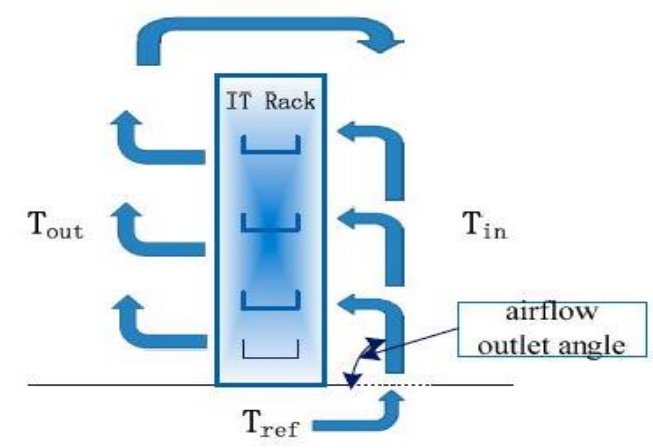

(b)

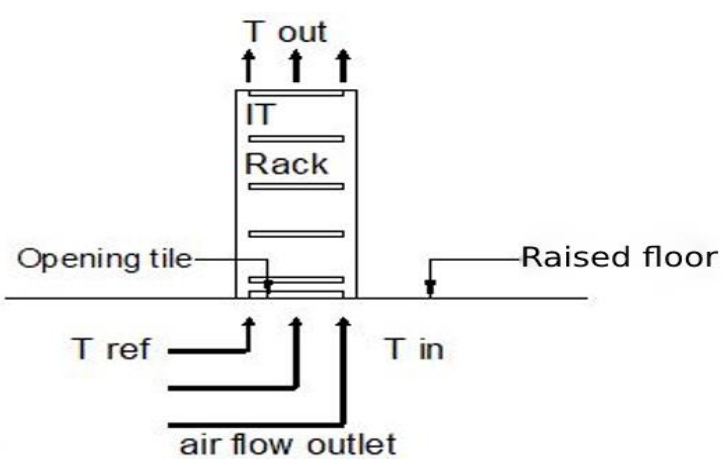

Fig. 2 Schematic diagram shows the direction of the air flow and temperature around the racks. (a) Common configuration. (b) Suggested configuration.

In this section, the geometry and arrangement of the data center under investigation will be described in detail.

The dimension of data center room is $6.71 \mathrm{~m} \times 5.49 \mathrm{~m} \times 3.0 \mathrm{~m}$ as shown in Fig. (3). The data center room contains two CRACs units are supplying cold air flow. This air is equally distributed between the CRACs at the same supply temperature. As it shown in Fig. (3), there are fourteen server racks, each of them has a dimension of $0.61 \mathrm{~m} \times 0.915$ $\mathrm{m} \times 2.0 \mathrm{~m}$. In this arrangement, each rack generates $3.5 \mathrm{~kW}$ of heat dissipation, and the racks are distributed on two rows, each row houses seven racks, with a spacing 1.22 $\mathrm{m}$ between the two rows and the racks rows are arranged to be at $1.22 \mathrm{~m}$ apart from the room walls. Each rack is assumed to include four server's chassis which generate heat. 
A typical raised floor has been employed, which contains fourteen perforated tiles to provide the supply cold air and fourteen racks with raised floor plenum height $0.6 \mathrm{~m}$. This perforated tiles represent $20 \%$ of the total floor area, where the size of each perforated tile is $0.6 \mathrm{~m} \times 0.6 \mathrm{~m}$. The cold air flows out through all tiles with the same temperature $12^{\circ} \mathrm{C}$. The hot air, which is discharged from the top of each rack servers, flows out from the room through six ceiling vents; three in each hot aisle as it shown in Fig. (3). The CRACs units discharge the cold air to the plenum These arrangement are investigated numerically using ANSYS 16. The geometry is created using AUTOCAD 18, then it is exported to ANSYS. The meshing is create using ANSYS workbench with taken into account several mesh refinement around the walls to keep the y+ small as possible. Constant mass flow is assumed at each tile, and consequently at each rack unit inlet. This arrangement has been chosen in order to validate with the work represented with those of Nada et al, [18].
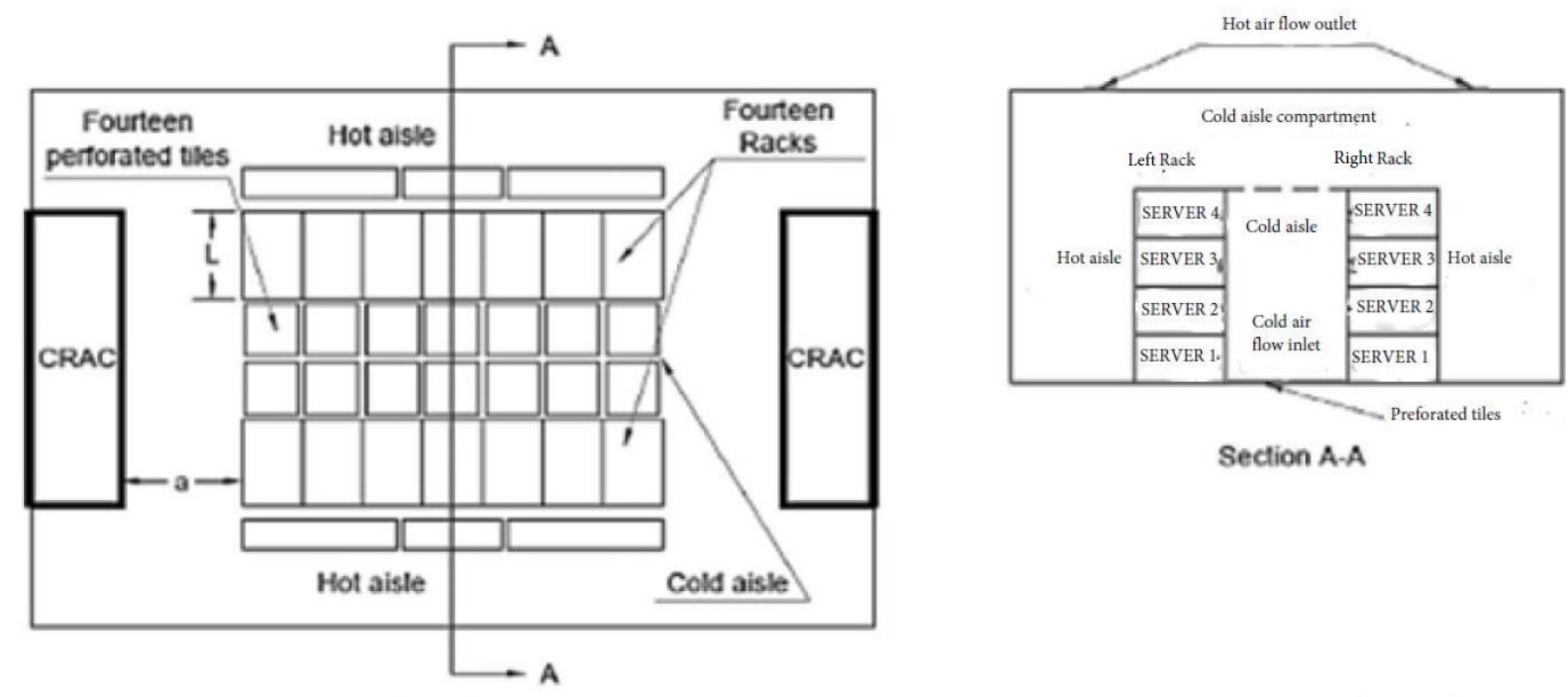

Fig. 3 A schematic diagram shows the arrangement of the racks and CRAC(s) units inside the computational domain. Left: a plane view. Right: sectional view at axis AA.

A specific data center with raised floor air supplying system was chosen as a targeted model, where measurements of energy consumption and thermal environments were available in the CFD study as in Refs. $[14,16]$. This combined with the modifications discussed in the previous sections. These available measurement and data are used to analyze and evaluate the results of the current studycase. 


\section{MATHEMATICAL FORMULATION, NUMERICAL TECHNIQUES AND MODEL VALIDATIONS}

As mentioned in the previous section, ANSYS-FLUENT 16.0 is used to simulate the current case. The initial values of velocity, flow rate, temperature, heat generation, tile porosity are tabulated in Table 1.

\section{Table 1 Initial values for the simulation}

\begin{tabular}{|l|c|c|}
\hline Boundary condition & Symbol & Value \\
\hline Inlet airflow velocity & $\mathrm{U}_{0}$ & $1 \mathrm{~ms}^{-1}$ \\
\hline Tile flow rate & $\mathrm{Q}_{\mathrm{t}}$ & $0.294 \mathrm{~m}^{3} \mathrm{~s}^{-1}$ \\
\hline Inlet air temperature & $\mathrm{T}_{0}$ & $12^{\circ} \mathrm{C}(285 \mathrm{~K})$ \\
\hline Flow rate per server & $\mathrm{Q}_{\mathrm{s}}$ & $0.0735 \mathrm{~m}^{3} \mathrm{~s}^{-1}$ \\
\hline Heat generation per server & $\mathrm{P}_{\mathrm{s}}$ & $875 \mathrm{~W}$ \\
\hline Tile porosity & - & $25 \%$ \\
\hline Rack porosity & - & $35 \%$ \\
\hline
\end{tabular}

In order to evaluate the cooling system in a data center, four performance indices are commonly used: (1) Return Temperature Index (RTI), (2) Supply Heat Index (SHI), (3) Return Heat Index (RHI), and (4) Rack Cooling Index (RCI). The RTI index is used to measure the energy performance of data center air management system as in [18].

$$
\mathrm{RTI}=\left[\frac{T_{\text {return }}-T_{\text {supply }}}{\Delta T_{\text {equipment }}}\right] \times 100 \%,
$$

where the $T_{\text {supply }}, T_{\text {return }}, \Delta T_{\text {equipment }}$ are the temperature at the rack inlet, 
temperature at the rack outlet, and supply and return temperature difference of the CRAC, respectively. The supply heat index (SHI) is defined as the ratio of the heat gained by the cold air before entering the racks to the total heat gain by the air after leaving the rack. SHI can be expressed in terms of rack inlet, rack outlet and CRAC outlet temperatures as follows, [18]

$$
\mathrm{SHI}=\left\{\frac{\sum_{j} \sum_{i}\left(\left(T_{\text {in }}^{r}\right) i, j-T_{r e f}\right)}{\sum_{j} \sum_{i}\left(\left(T_{\text {out }}^{r}\right) i, j-T_{r e f}\right)}\right\},
$$

Where $T_{i n}^{r}$ is the rack intake airflow temperature, $T_{r e f}$ is the airflow supply temperature from CRAC unit and $T_{\text {out }}^{r}$ is the airflow temperature exhaust from rack. The return heat index (RHI) is defined as the ratio of the total heat extracted by the CRAC units to the total enthalpy rise at the rack exhaust, [18]

$$
\mathrm{RHI}=\left\{\frac{\sum_{j} \sum_{i} \boldsymbol{M}_{k} \boldsymbol{C}_{p}\left(\left(\boldsymbol{T}_{\text {in }}^{c}\right) \boldsymbol{k}-\boldsymbol{T}_{\text {ref }}\right)}{\sum_{j} \sum_{i} \boldsymbol{m}_{i, j}^{r} \boldsymbol{C}_{\boldsymbol{p}}\left(\left(\boldsymbol{T}_{\text {out }}^{r}\right) \boldsymbol{i}_{j}-\boldsymbol{T}_{\text {ref }}\right)}\right\},
$$

Where $\boldsymbol{M}_{\boldsymbol{k}}$ is the mass flow rate supply from CRAC unit, $\boldsymbol{m}_{\boldsymbol{i}, \boldsymbol{j}}^{\boldsymbol{r}}$ the mass flow rate across equipment and $\boldsymbol{T}_{\text {in }}^{\boldsymbol{c}}$ the airflow return temperature at CRAC.

RHI can be considered as a complement to SHI as it is clear from Eqs. (2) and (3), where the summation of both SHI and RHI equal unity. Return temperature index (RTI) relates the rack inlet temperatures with its allowable and recommended ranges for reliable facility continuous operation.

Two RCIs, namely RCIHI and RCILO, were used to measure the server's intake temperatures with respect to these limits. RCIHI and RCILO measure the over and under temperatures, respectively and can be defined by, [18]

$$
\begin{aligned}
& R C I_{H I}=\left\{1-\frac{\text { TOTAL OVER PRESSURE }}{\text { MAX ALLOWABLE OVER PRESSURE }}\right\} 100 \%, \\
& R C I_{L O}=\left\{1-\frac{\text { TOTAL UNDER PRESSURE }}{\text { MAX ALLOWABLE UNDER PRESSURE }}\right\} 100 \%,
\end{aligned}
$$

Over-temperature means that the server intake temperature exceeds the maximum recommended one. The total over-temperature is the summation of over-temperatures of 
all rack servers. Similarly, under-temperature means that the intake temperatures becomes below the minimum recommended. The overall performance parameters indices (SHI, RHI and RTI) were calculated in the current simulation at three different mesh sizes to check the result convergence. The results of grid-independent study are illustrated in Table 2.

Table 2 Effect of different grid sizes on measurable overall performance indices (SHI, RHI, and RTI)

\begin{tabular}{|l|l|l|l|l|l|l|}
\hline $\begin{array}{l}\text { Number } \\
\text { of mesh }\end{array}$ & $\begin{array}{l}\text { Right rack } \\
\text { RTI }\end{array}$ & $\begin{array}{l}\text { Left rack } \\
\text { RTI }\end{array}$ & $\begin{array}{l}\text { Right rack } \\
\text { SHI }\end{array}$ & $\begin{array}{l}\text { Left } \\
\text { rack } \\
\text { SHI }\end{array}$ & $\begin{array}{l}\text { Right } \\
\text { rack } \\
\text { RHI }\end{array}$ & $\begin{array}{l}\text { Left } \\
\text { rack } \\
\text { RHI }\end{array}$ \\
\hline 690,193 & $110 \%$ & $110 \%$ & 0.13 & 0.15 & 0.87 & 0.85 \\
\hline $1,086,271$ & $110 \%$ & $110 \%$ & 0.13 & 0.15 & 0.87 & 0.85 \\
\hline $2,193,889$ & $110 \%$ & $110 \%$ & 0.13 & 0.15 & 0.87 & 0.85 \\
\hline
\end{tabular}

The above results are compared to the results in [18] which are indicated in table 3.

Table 3 Effect of different grid sizes as in [18] simlation on measurable overall performance indices (SHI, RHI, and RTI)

\begin{tabular}{|l|l|l|l|l|l|l|}
\hline $\begin{array}{l}\text { Number } \\
\text { of mesh }\end{array}$ & $\begin{array}{l}\text { Right rack } \\
\text { RTI }\end{array}$ & $\begin{array}{l}\text { Left rack } \\
\text { RTI }\end{array}$ & $\begin{array}{l}\text { Right rack } \\
\text { SHI }\end{array}$ & $\begin{array}{l}\text { Left } \\
\text { rack } \\
\text { SHI }\end{array}$ & $\begin{array}{l}\text { Right } \\
\text { rack } \\
\text { RHI }\end{array}$ & $\begin{array}{l}\text { Left } \\
\text { rack } \\
\text { RHI }\end{array}$ \\
\hline $3,220,343$ & $121 \%$ & $121 \%$ & 0.2 & 0.19 & 0.8 & 0.81 \\
\hline $3,593,599$ & $121 \%$ & $121 \%$ & 0.2 & 0.19 & 0.8 & 0.81 \\
\hline $4,231,343$ & $121 \%$ & $121 \%$ & 0.2 & 0.19 & 0.8 & 0.81 \\
\hline
\end{tabular}

\section{Results}

In this section, three cases with three different meshes, will be discussed, then the converged simulation will be analyzed. The details are summarized in the following sections. 


\subsection{Mesh independent study}

The data center performance index SHI, RHI, RTI in the current simulation (Fig. 4) are analyzed with difference meshes (Cases); Case I: 690193 grid points, Case II: 1086271 grid points, and Case III: 2193889 grid points. It has been found that the performance and temperature contours of the data center is improved compared to the results of Ref. [18] with a reduced RTI by $11 \%$ and a reduced SHI of the left and right racks by 0.04 and 0.07 respectively with also an increase in RHI of the left and right racks by 0.04 and 0.07 respectively.

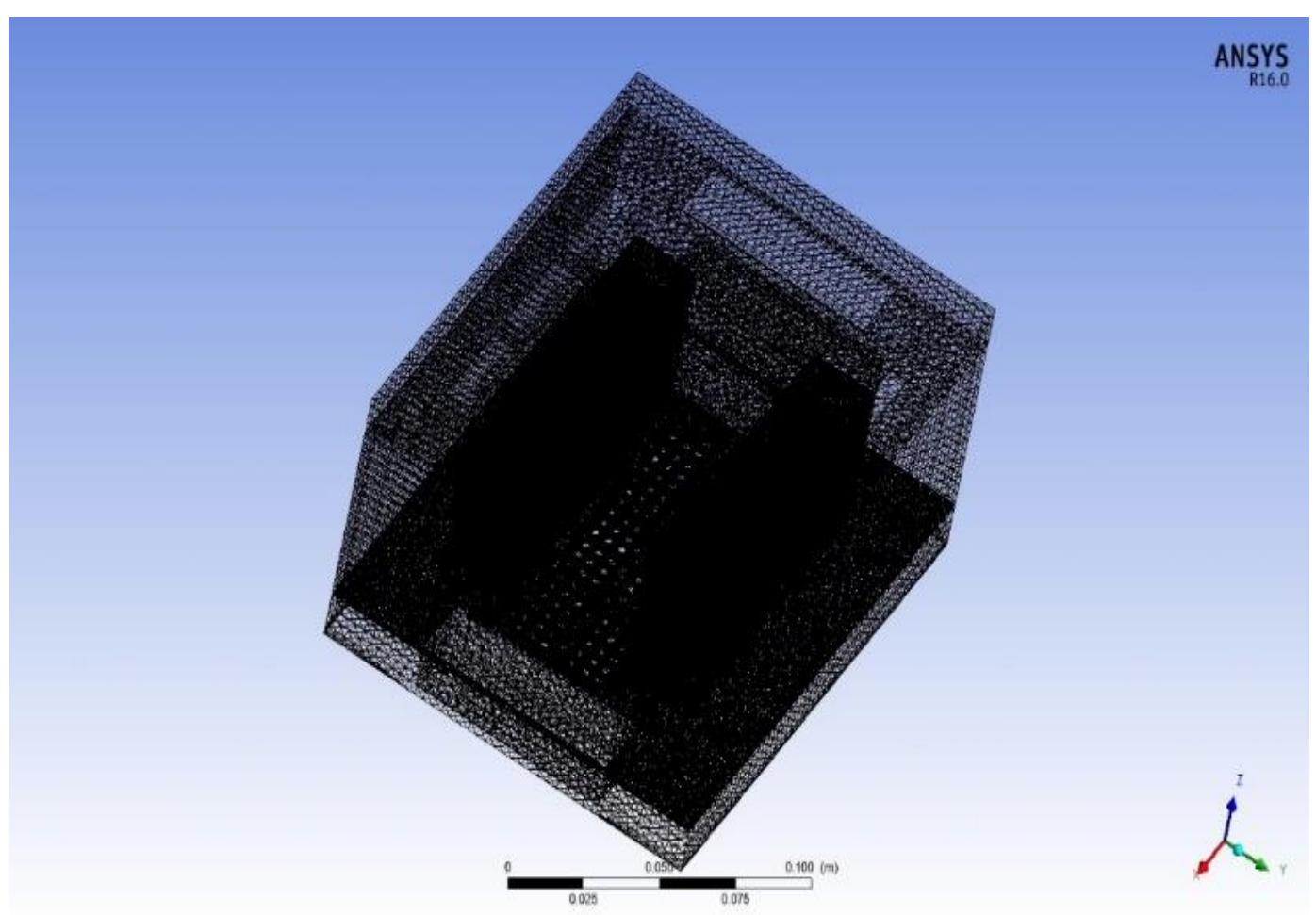

Fig. 4a The mesh topology 


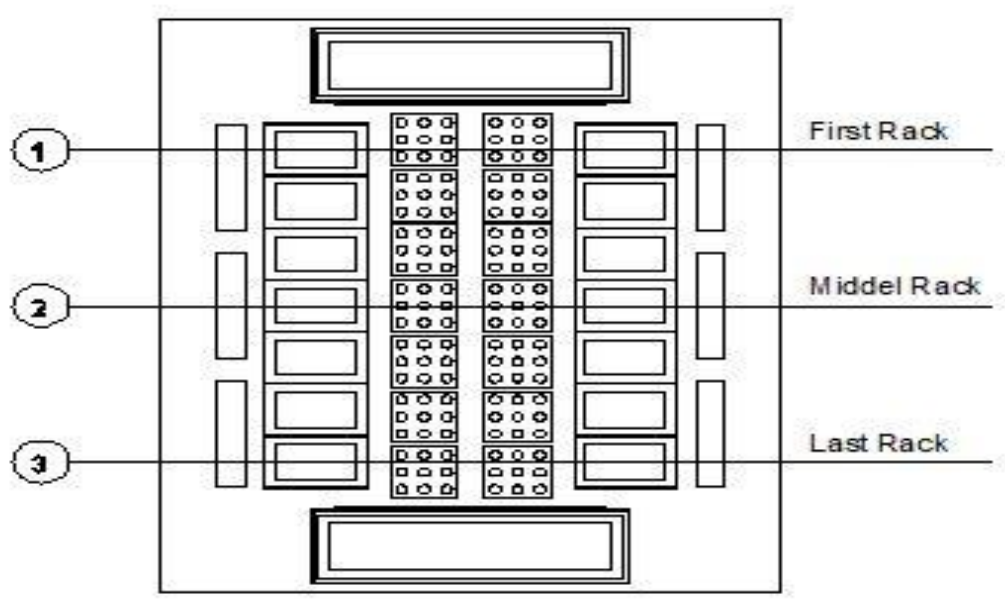

Fig. 4b The mesh topology

\subsubsection{Velocity and temperature profile in Case I}

Figures 5-9 show the color contour for the temperature (Left) and the flow velocity (Right) at different sections and racks. Everything seems to be as it is expected. From these figures, it can be observed that the maximum temperature found inside the racks and has a maximum value which reaches $45^{\circ} \mathrm{C}$ as shown in the figures. The average temperature reaches $22^{\circ} \mathrm{C}$; this temperature value is acceptable as indicated in Appendix A (Table A1 and Figs. A1-A3). Also, it can be observed that the average temperature in the cold aisles is $13^{\circ} \mathrm{C}$, and it is $17{ }^{\circ} \mathrm{C}$ at top of the rack, whereas it reaches $22{ }^{\circ} \mathrm{C}$ in the hot aisles. These values agree very well with the standard values as indicated in Appendix A (Table A1). Fig. 10 shows the maximum velocity (Fig. 10 (Left)) and maximum temperature (Fig. 10 (Right)) in the domain. It has been observed that the maximum velocity value $(2.31 \mathrm{~m} / \mathrm{s})$ can be found near to the first rack, the second peak is found at the middle rack $(2.06 \mathrm{~m} / \mathrm{s})$ as shown in Fig. 10 because they are far away from the CRAC. The maximum temperature in the domain seems to be similar near to all racks as shown in Fig. 10(Right); it reaches 318.8 K. 
Momtaz Sedrak / Engineering Research Journal 168 (Decamber2020) M1- M29

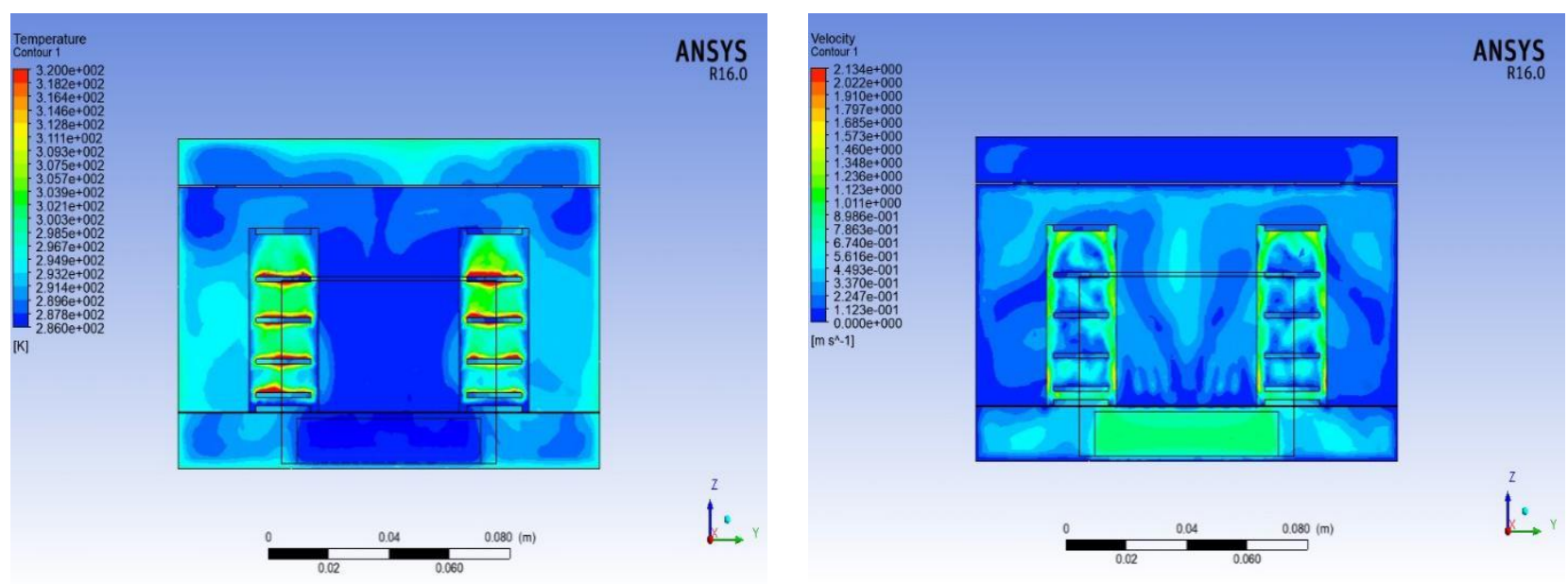

Fig. 5 First rack (Case I). Left: Temperature. Right: velocity contour.
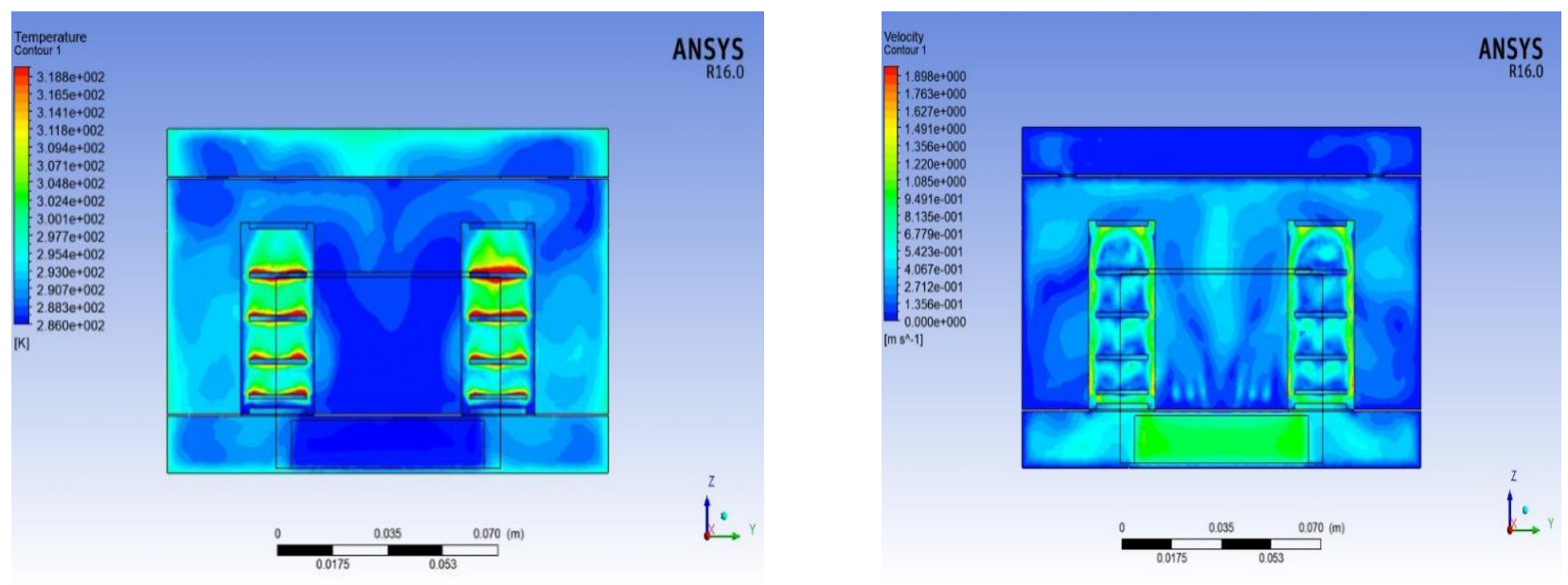

Fig. 6 Last rack (Case I). Left: Temperature. Right: velocity contour. 
Momtaz Sedrak / Engineering Research Journal 168 (Decamber2020) M1- M29
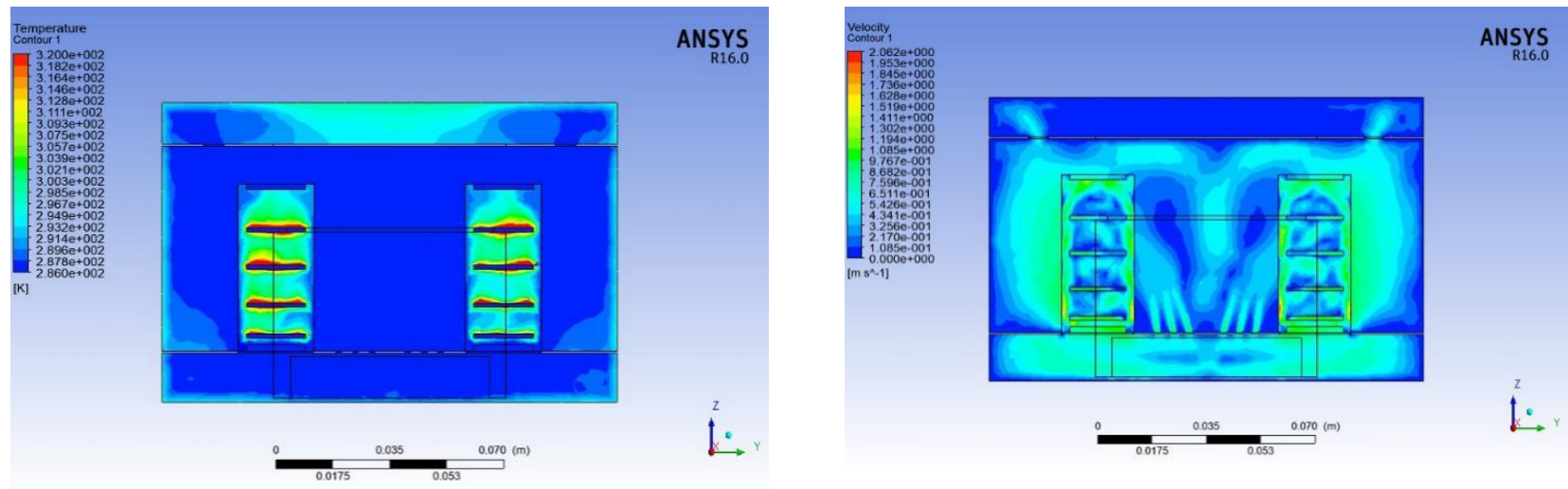

Fig. 7 Middle rack (Case I). Left: Temperature. Right: velocity contour.
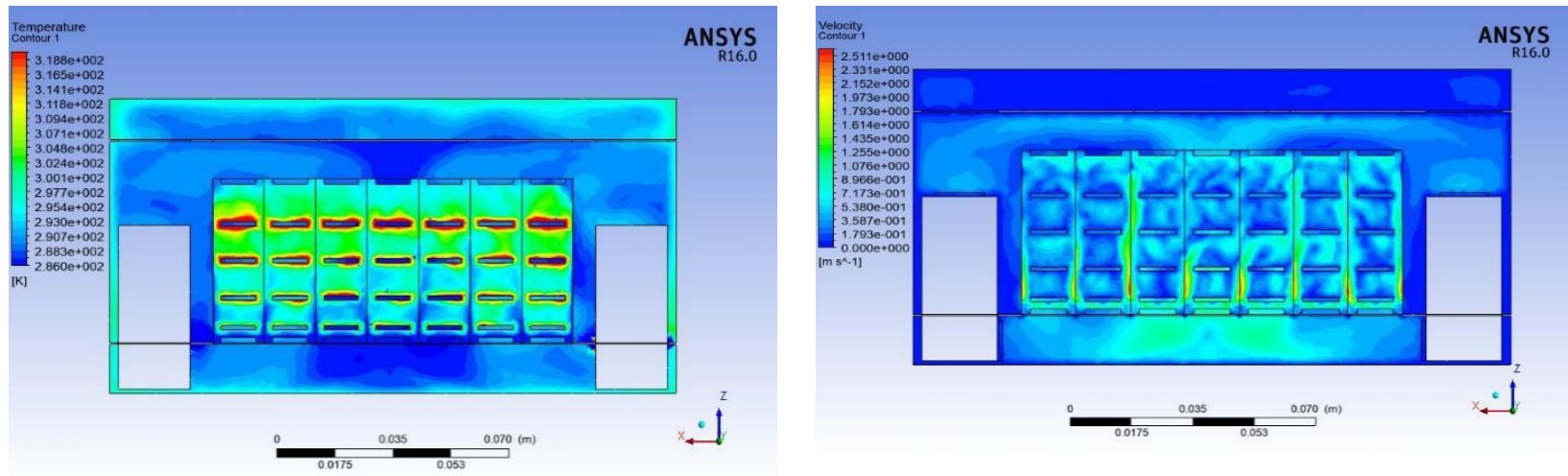

Fig. 8 Left rack (Case I). Left: Temperature. Right: velocity contour.

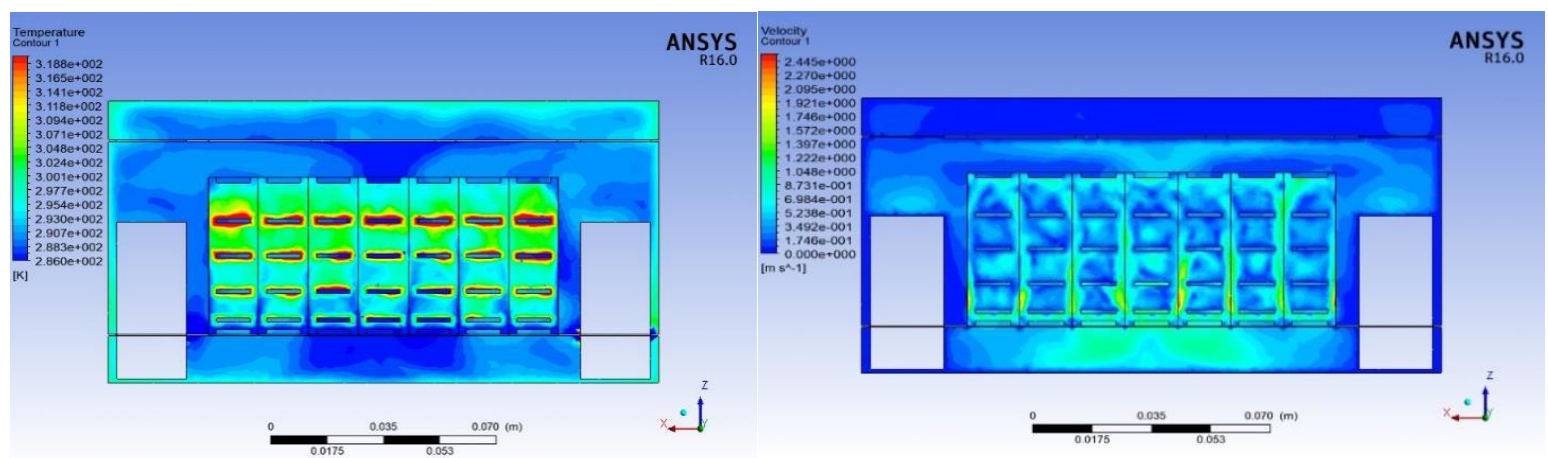

Fig. 9 Right rack (Case I). Left: Temperature. Right: velocity contour. 
Momtaz Sedrak / Engineering Research Journal 168 (Decamber2020) M1- M29
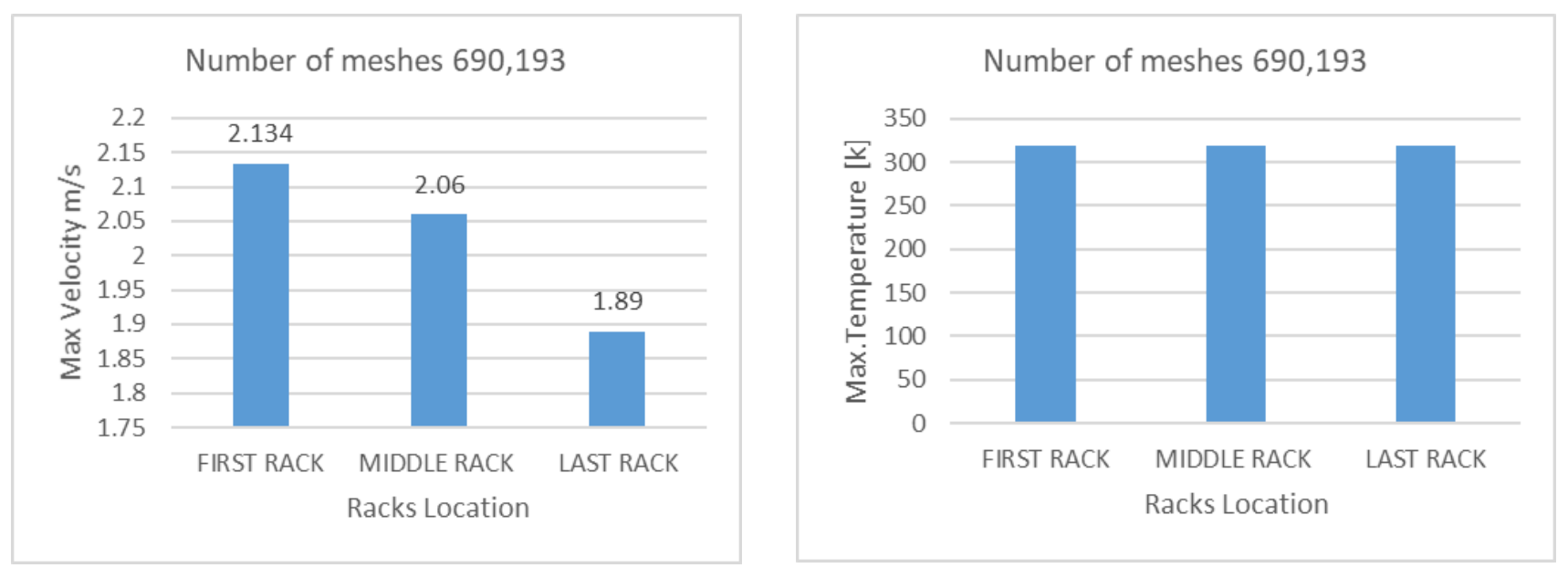

Fig. 10 Maximum values in Case I. Left: maximum velocity. Right: maximum temperature.

\subsubsection{Velocity and temperature profile in Case II}

Figures 11-16 show the color contour for the temperature (Left) and the flow velocity (Right) at different sections and racks. Everything seems to be as it is expected. From these figures, it can be observed that the maximum temperature found inside the racks and has a maximum value which reaches $47^{\circ} \mathrm{C}$ as shown in the figures. The average temperature reaches $22^{\circ} \mathrm{C}(295 \mathrm{~K})$; this temperature value is acceptable as indicated in Appendix A (Table A1 and Figs. A1-A3). Also, it can be observed that the average temperature in the cold aisles is $12.5^{\circ} \mathrm{C}$, and it is $17^{\circ} \mathrm{C}$ at top of the rack, whereas it reaches $21{ }^{\circ} \mathrm{C}$ in the hot aisles. These values agree very well with the standard values as indicated in Appendix A (Table A1). Fig. 17 shows the maximum velocity (Fig. 17 (Left)) and maximum temperature (Fig. 17 (Right)) in the domain. It has been observed that the maximum velocity value $(2.22 \mathrm{~m} / \mathrm{s})$ can be found near to the middle rack, the second peak is found at the last rack $(2.04 \mathrm{~m} / \mathrm{s})$ as shown in Fig. 10 because they are far away from the CRAC. The maximum temperature in the domain seems to be similar near to all racks as shown in Fig. 17(Right); it reaches $320 \mathrm{~K}$. 

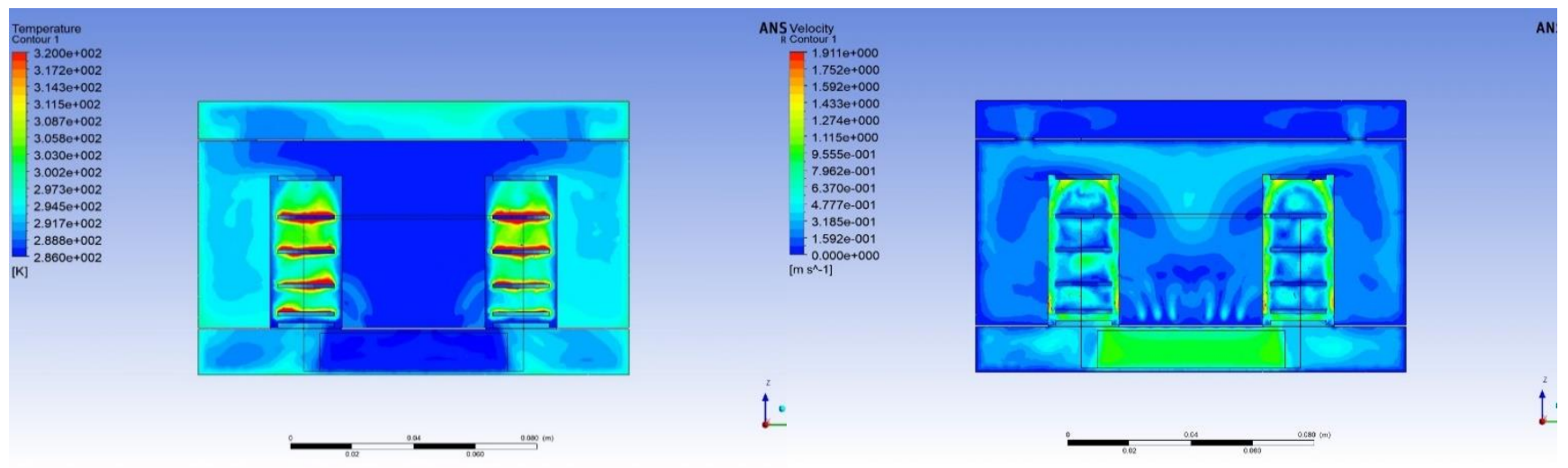

Fig. 11 First rack (Case II). Left: Temperature. Right: velocity contour.

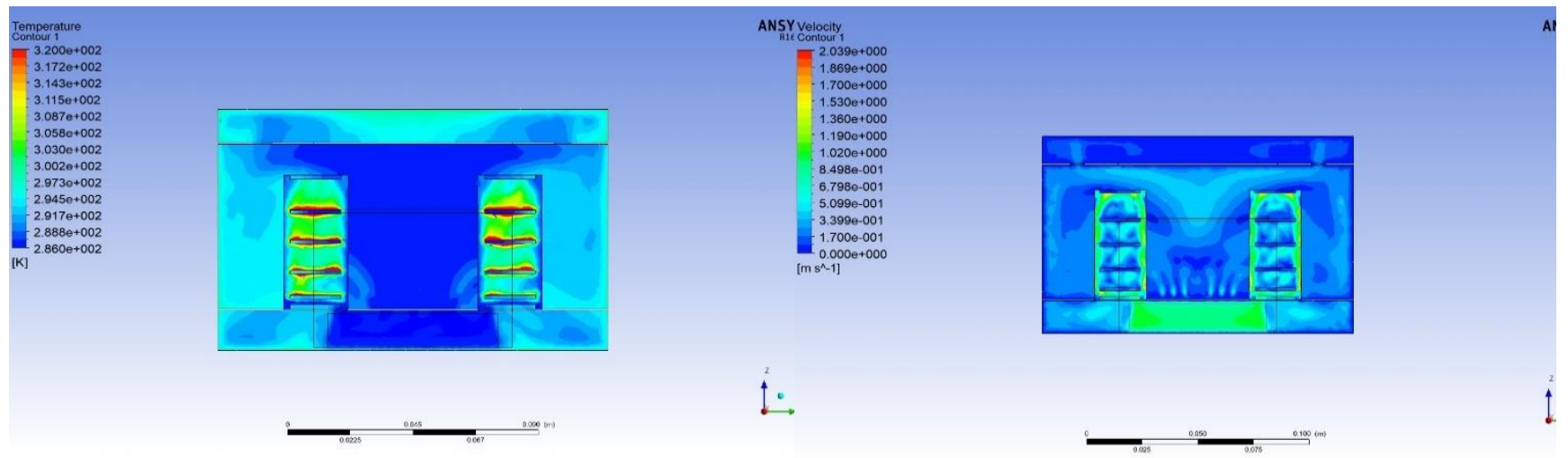

Fig. 12 Last rack (Case II). Left: Temperature. Right: velocity contour.

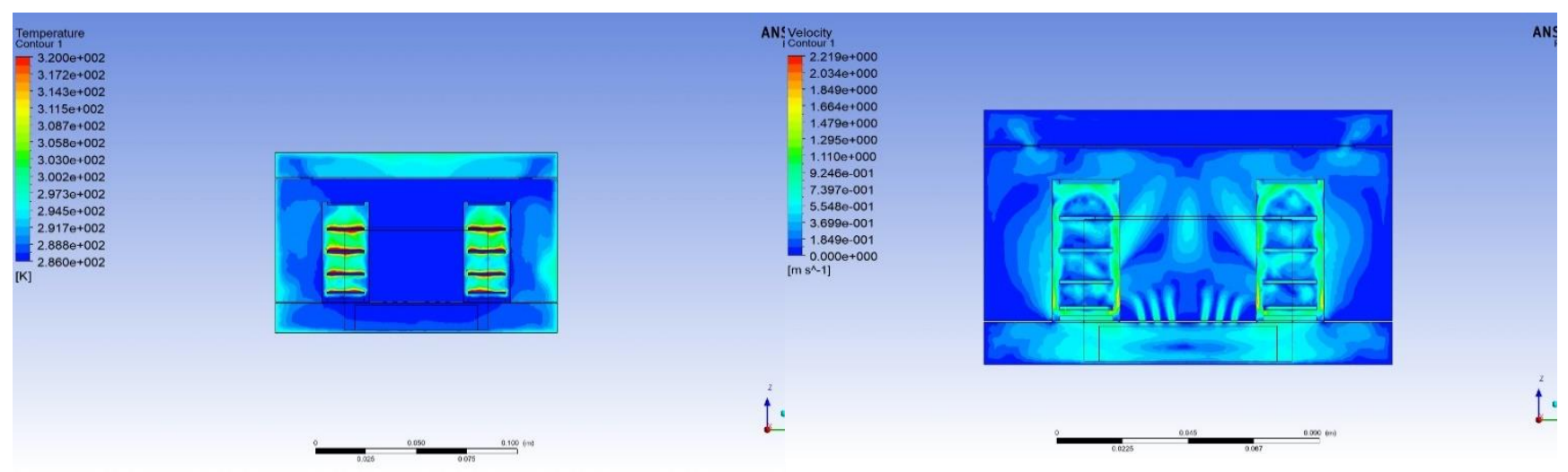

Fig. 13 Middle rack (Case II), Left: Temperature. Right: velocity contour. 
Momtaz Sedrak / Engineering Research Journal 168 (Decamber2020) M1- M29
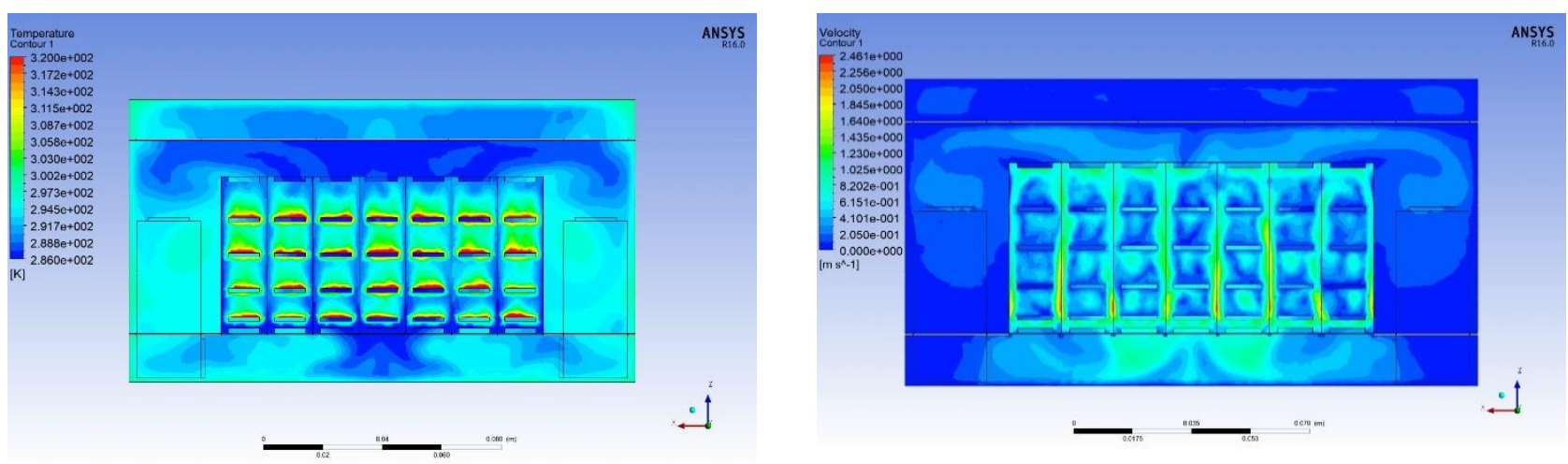

Fig. 14 Left rack (Case II), Left: Temperature. Right: velocity contour.
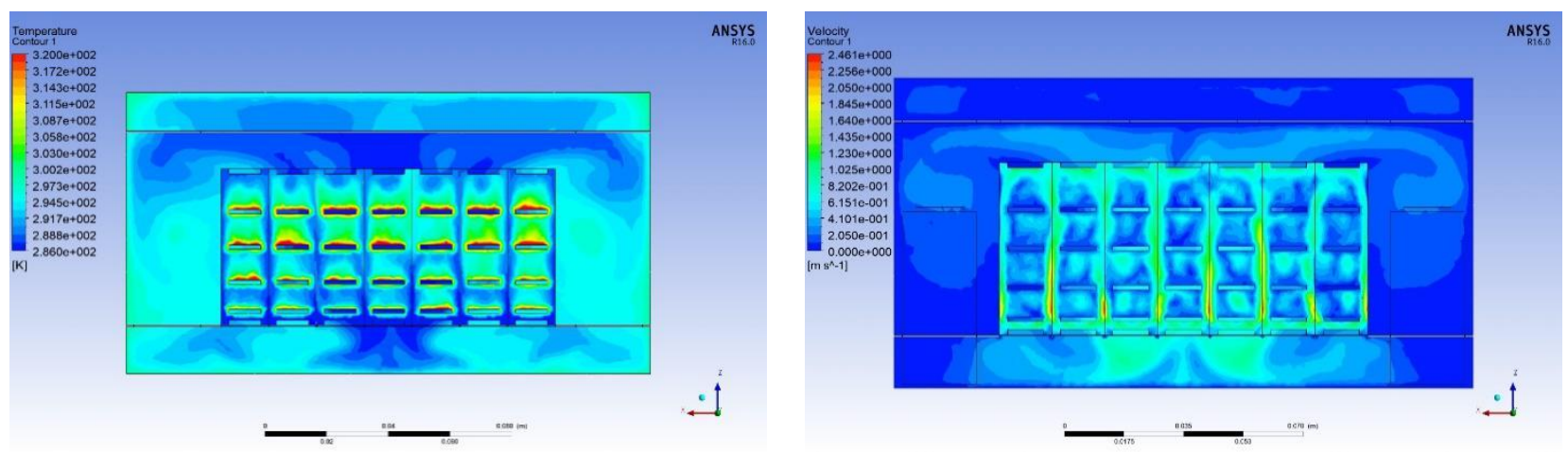

Fig. 15 Right rack (Case II), Left: Temperature. Right: velocity contour.

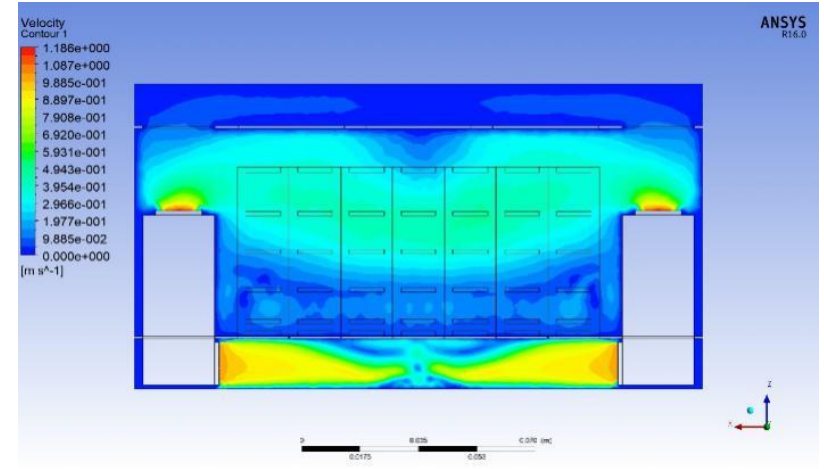

Fig. 16 Velocity contour in middle of room in (Case II). 
Momtaz Sedrak / Engineering Research Journal 168 (Decamber2020) M1- M29
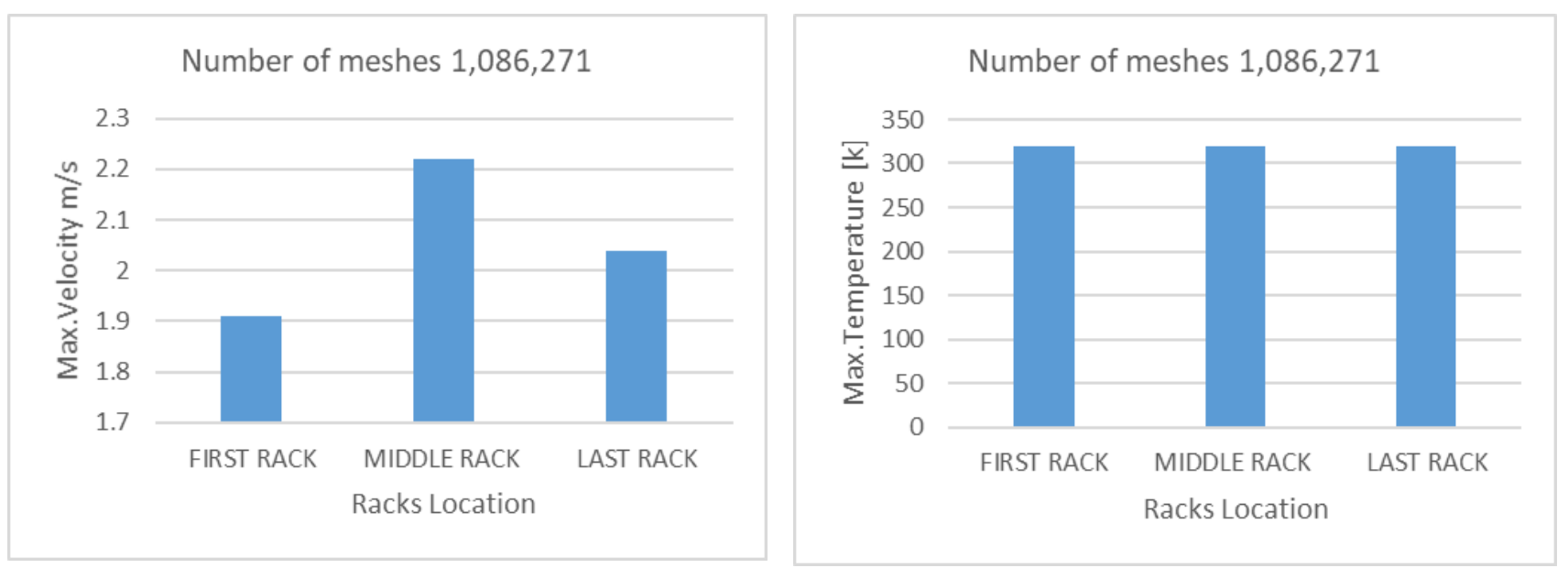

Fig. 17 Maximum values in Case II. Left: maximum velocity. Right: maximum temperature.

\subsubsection{Velocity and temperature profile in Case III}

Figures 18-22 show the color contour for the temperature (Left) and the flow velocity (Right) at different sections and racks. Again, everything seems to be as it is expected. From these figures, it can be observed that the maximum temperature found inside the racks and has a maximum value which reaches $47^{\circ} \mathrm{C}(320.15 \mathrm{~K})$ as shown in the figures. The average temperature reaches $22^{\circ} \mathrm{C}(295.15 \mathrm{~K})$; this temperature value is acceptable as indicated in Appendix A (Table A1 and Figs. A1-A3). Also, it can be observed that the average temperature in the cold aisles is $14^{\circ} \mathrm{C}(287.15 \mathrm{~K})$, and it is $15^{\circ} \mathrm{C}(288.15 \mathrm{~K})$ at top of the rack, whereas it reaches $22{ }^{\circ} \mathrm{C}(295.15 \mathrm{~K})$ in the hot aisles. These values agree very well with the standard values as indicated in Appendix A (Table A1). Fig. 23 shows the maximum velocity (Fig. 23 (Left)) and maximum temperature (Fig. 23 (Right)) in the domain. It has been observed that the maximum velocity value $(2.23 \mathrm{~m} / \mathrm{s})$ can be found near to the middle rack, the second peak is found at the first rack (2.16 $\mathrm{m} / \mathrm{s}$ ) as shown in Fig. 23 because they are far away from the CRAC. The maximum temperature in the domain seems to be similar near to all racks as shown in Fig. 23(Right); it reaches $320 \mathrm{~K}$. 
Momtaz Sedrak / Engineering Research Journal 168 (Decamber2020) M1- M29
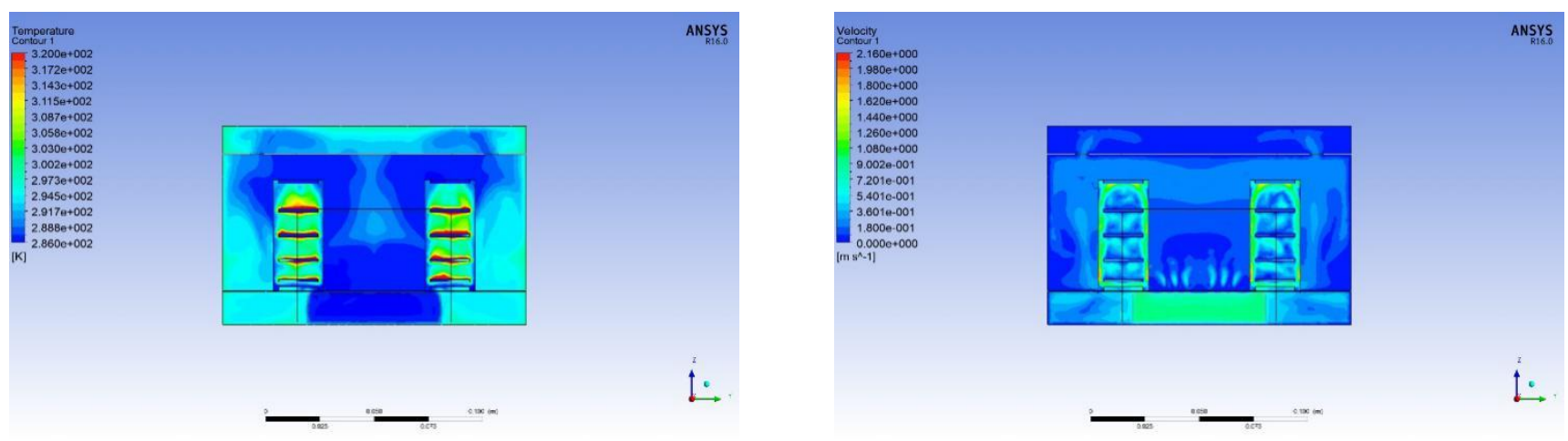

Fig. 18 First rack (Case III). Left: Temperature. Right: velocity contour.

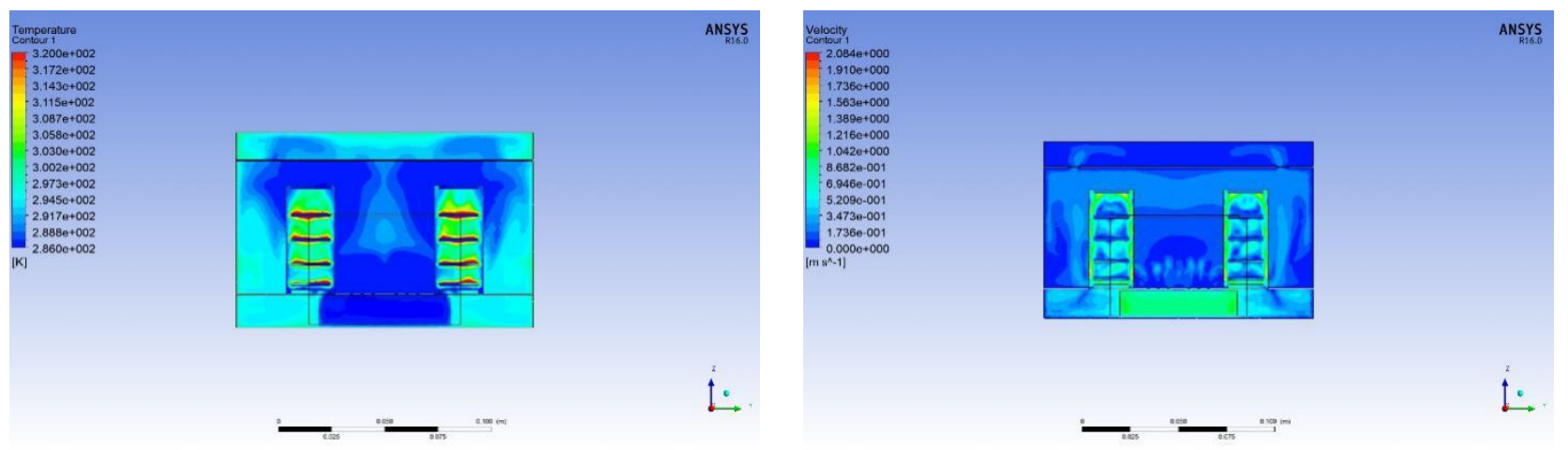

Fig. 19 Last rack (Case III). Left: Temperature. Right: velocity contour.

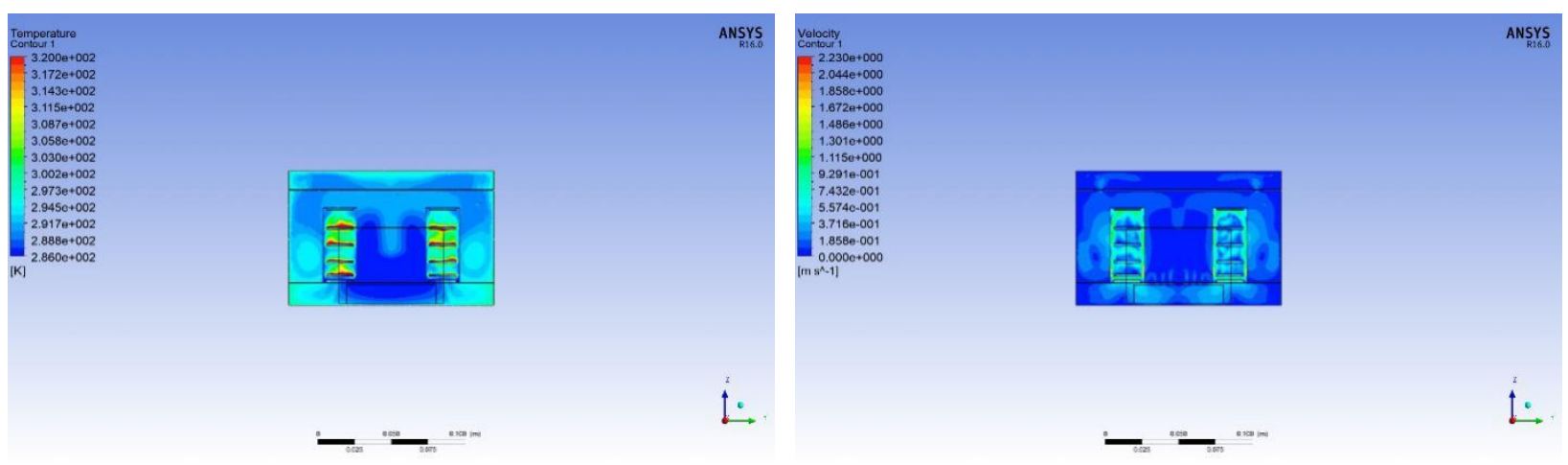

Fig. 20 Middle rack (Case III). Left: Temperature. Right: velocity contour. 

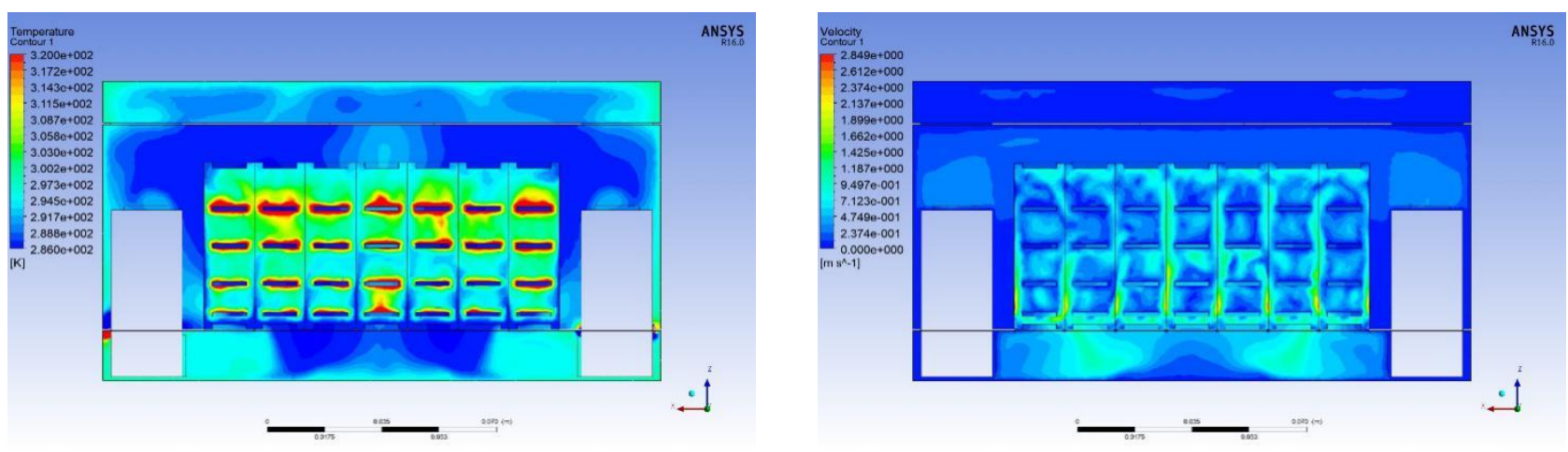

Fig. 21 Right rack (Case III). Left: Temperature. Right: velocity contour.
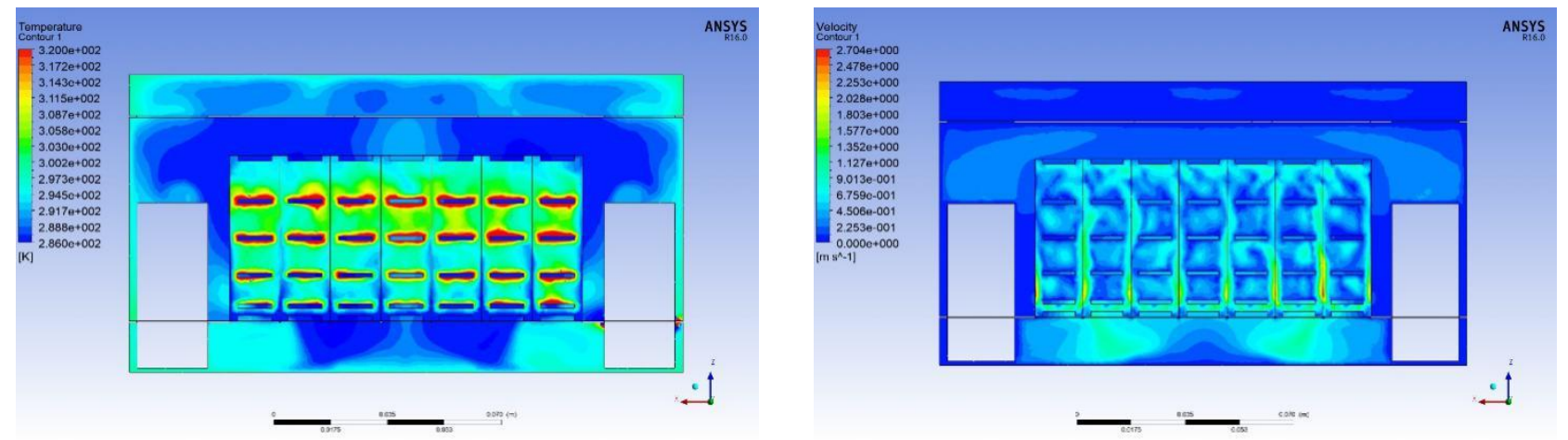

Fig. 22 Left rack (Case III). Left: Temperature. Right: velocity contour.
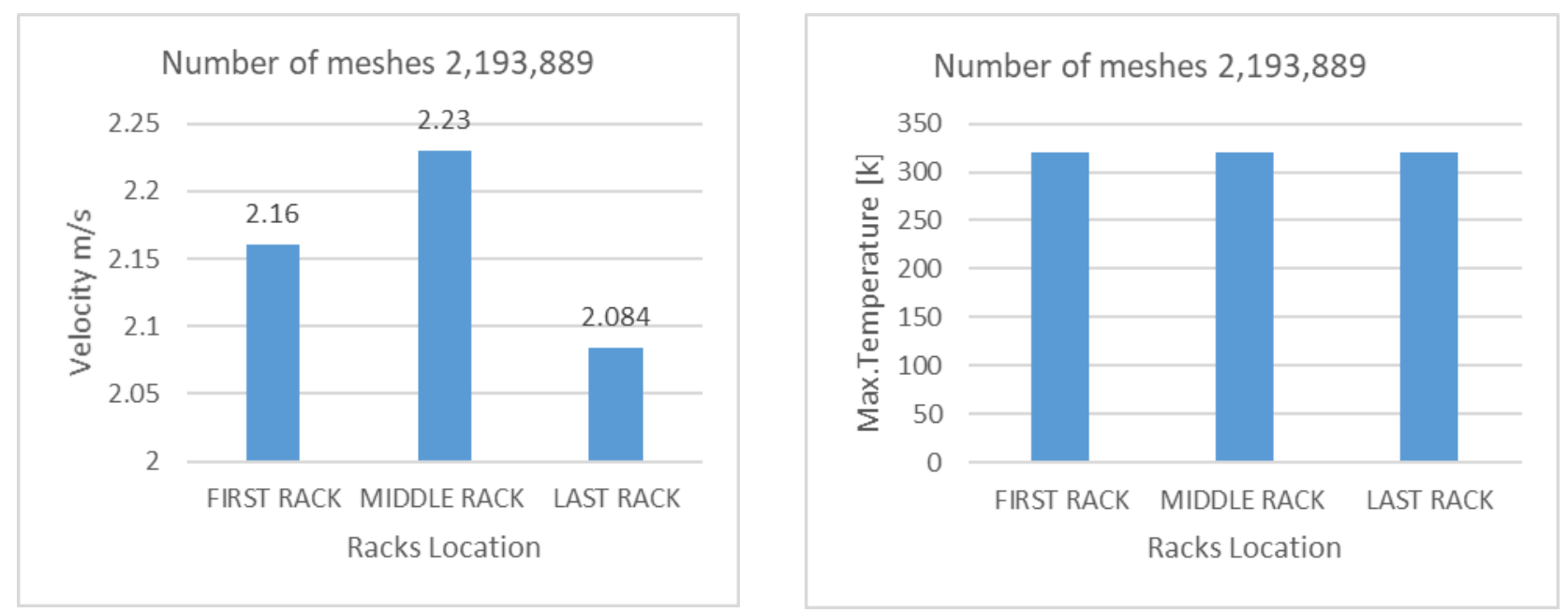

Fig. 23 Maximum values in Case III. Left: maximum velocity. Right: maximum temperature. 


\subsubsection{Velocity and temperature profiles comparison among the three cases}

Figures 24 and 25 compare the maximum and minimum velocity in the domain between the three cases. It has been observed that the maximum value can be found near to the middle rack as shown in Fig 24; it reaches to $2.23 \mathrm{~m} / \mathrm{s}$ in Case III, while the minimum velocity reaches $1.89 \mathrm{~m} / \mathrm{s}$ in Case I.The maximum temperature is about $45{ }^{\circ} \mathrm{C}(318.15 \mathrm{~K})$ in the three cases. These mean that the velocity is more sensitive to the selected mesh size and it should be noticed that the more number of meshes the more it is closer to reality the more accurate the velocity.

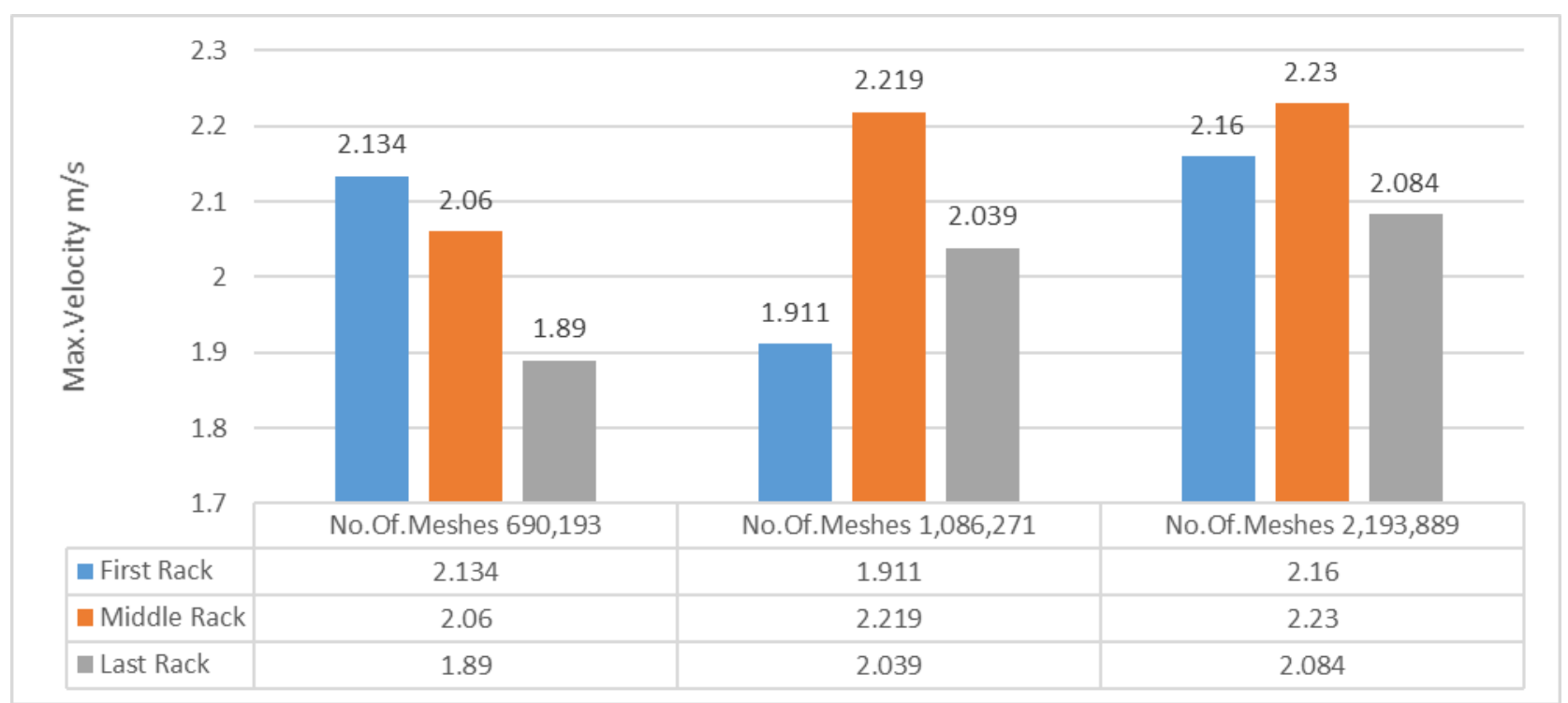

Fig. 24 Maximum velocity for the three cases. 


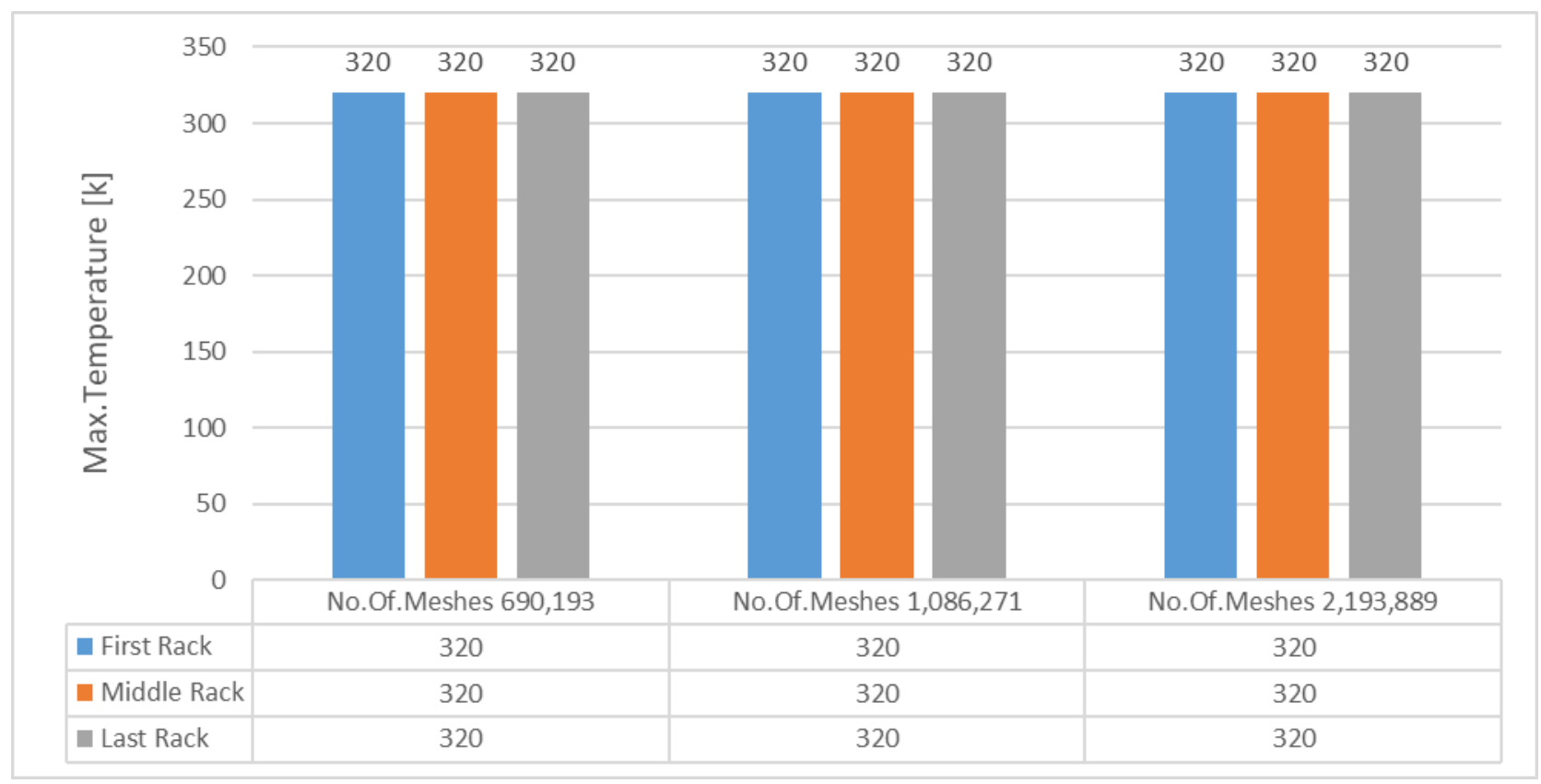

Fig. 25 Maximum temperature for the three cases.

\section{Conclusions}

In this work, a novel arrangement of several units inside a data center is introduced through two modifications: (1) modifying the locations of heat sources (racks units) and cooling machines (CRAC units), and the airflow distribution path; where the suggested arrangement is different than the standard one, and (2) changing the location of the server fan compared to the standard one. As a first step, the quality of the numerical simulation of the suggested modifications was evaluate by testing three different mesh sizes: Case I (690 193 cells), Case II (1 086271 cells), and Case III (2 193889 cells). It has been found the temperature doesn't change much with increasing the number of cells, while the air flow velocity is more sensitive to the number of the mesh cells. Additionally, it was found that the suggested modifications in fans position to be on the rack top instead of on the side increase the cooling performance and reduces energy consumption compared to the traditional arrangements.

\section{References}

[1] "Data centres and data transmission networks - Tracking Buildings - Analysis IEA.” [Online]. Available: https://www.iea.org/reports/tracking-buildings/data-centresand-data-transmission-networks. [Accessed: 04-May-2020]. 
[2] S. A. Nada, K. E. Elfeky, A. M. A. Attia, and W. G. Alshaer, "Experimental parametric study of servers cooling management in data centers buildings," Heat Mass Transf. und Stoffuebertragung, vol. 53, no. 6, pp. 2083-2097, 2017, doi: 10.1007/s00231-017-1966-y.

[3] S. A. Nada and K. E. Elfeky, "Experimental investigations of thermal managements solutions in data centers buildings for different arrangements of cold aisles containments,” J. Build. Eng., vol. 5, pp. 41-49, 2016, doi: 10.1016/j.jobe.2015.11.001.

[4] C. Lyu, G. Chen, S. Ye, and Y. Liu, "Enclosed aisle effect on cooling efficiency in small scale data center," Procedia Eng., vol. 205, pp. 3789-3796, 2017, doi: 10.1016/j.proeng.2017.10.132.

[5] Mohammed Faisal K and Dr. Jeoju M Issac, "Analysis and Performance Prediction of Data Centre with Different Configurations using CFD," Int. J. Eng. Res., vol. V4, no. 10, pp. 570-575, 2015, doi: 10.17577/ijertv4is100578.

[6] R. Schmidt, K. Karki, and S. Patankar, "Raised-floor data center: Perforated tile flow rates for various tile layouts," in Thermomechanical Phenomena in Electronic Systems -Proceedings of the Intersociety Conference, 2004, vol. 1, pp. 571-578, doi: 10.1109/itherm.2004.1319226.

[7] Y. Yang, B. Wang, and Q. Zhou, "Energy Saving Analysis of Free Cooling System in the Data Center," Procedia Eng., vol. 205, pp. 1815-1819, 2017, doi: 10.1016/j.proeng.2017.10.239.

[8] S. Shrivastava, R. Schmidt, B. Sammakia, and M. Iyengar, "Comparative analysis of different data center airflow management configurations," in Proceedings of the ASME/Pacific Rim Technical Conference and Exhibition on Integration and Packaging of MEMS, NEMS, and Electronic Systems: Advances in Electronic Packaging 2005, 2005, vol. PART A, pp. 329-336, doi: 10.1115/ipack2005-73234. 
[9] K. C. Karki, S. V. Patankar, and A. Radmehr, "Techniques for controlling airflow distribution in raised-floor data centers," in Advances in Electronic Packaging, 2003, vol. 2, pp. 621-628, doi: 10.1115/ipack2003-35282.

[10] S. Bhopte, D. Agonafer, R. Schmidt, and B. Sammakia, "Optimization of data center room layout to minimize rack inlet air temperature," J. Electron. Packag. Trans. ASME, vol. 128, no. 4, pp. 380-387, 2006, doi: 10.1115/1.2356866.

[11] J. W. VanGilder and R. R. Schmidt, "Airflow uniformity through perforated tiles in a raised-floor data center," Proc. ASME/Pacific Rim Tech. Conf. Exhib. Integr. Packag. MEMS, NEMS, Electron. Syst. Adv. Electron. Packag. 2005, vol. PART A, pp. 493-502, 2005, doi: 10.1115/ipack2005-73375.

[12] Z. Huang, K. Dong, Q. Sun, L. Su, and T. Liu, "Numerical Simulation and Comparative Analysis of Different Airflow Distributions in Data Centers," Procedia Eng., vol. 205, pp. 2378-2385, 2017, doi: 10.1016/j.proeng.2017.09.854.

[13] L. Ling, Q. Zhang, and L. Zeng, "Performance and energy efficiency analysis of data center cooling plant by using lake water source," Procedia Eng., vol. 205, pp. 30963103, 2017, doi: 10.1016/j.proeng.2017.10.313.

[14] K. Dong, P. Li, Z. Huang, L. Su, and Q. Sun, "Research on Free Cooling of Data Centers by Using Indirect Cooling of Open Cooling Tower," Procedia Eng., vol. 205, pp. 2831-2838, 2017, doi: 10.1016/j.proeng.2017.09.902.

[15] J. Cho, T. Lim, and B. S. Kim, "Measurements and predictions of the air distribution systems in high compute density (Internet) data centers," Energy Build., vol. 41, no. 10, pp. 1107-1115, 2009, doi: 10.1016/j.enbuild.2009.05.017.

[16] H. Fernando, J. Siriwardana, and S. Halgamuge, "Can a data center heat-flow model be scaled down?," in ICIAFS 2012 - Proceedings: 2012 IEEE 6th International 
Conference on Information and Automation for Sustainability, 2012, pp. 273-278, doi: 10.1109/ICIAFS.2012.6419916.

[17] C. Jin, X. Bai, and C. Yang, "Effects of airflow on the thermal environment and energy efficiency in raised-floor data centers: A review," Sci. Total Environ., vol. 695, 2019, doi: 10.1016/j.scitotenv.2019.133801.

[18] S. A. Nada, M. A. Said, and M. A. Rady, "ORIGINAL ARTICLE CFD investigations of data centers thermal performance for different configurations of CRACs units and aisles separation," Alexandria Eng. J., vol. 55, no. 2, pp. 959-971, 2016, doi: 10.1016/j.aej.2016.02.025.

[19] D. Centers, T. Spaces, and E. Equipment, "Data Center Power Equipment Thermal Guidelines and Best Practices Whitepaper created by ASHRAE Technical Committee ( TC ) 9.9 Mission Critical Facilities, Data Centers, Technology Spaces, and Electronic Equipment," 2016.

Appendix A

The recommended limits are normally given by codes and guideline in Table A1

\begin{tabular}{|c|c|c|c|c|c|}
\hline \multirow{2}{*}{ Class } & \multicolumn{2}{|c|}{ Allowable } & \multicolumn{2}{c|}{ Recommended } & Dew-point \\
& DB $\left({ }^{\mathrm{O}} \mathrm{C}\right)$ & $\mathrm{RH} \%$ & $\mathrm{DB}\left({ }^{\mathrm{O}} \mathrm{C}\right)$ & $\mathrm{RH} \%$ & $\left({ }^{\circ} \mathrm{C}\right)$ \\
\hline A1 & $15-32$ & $20-80$ & $18-27$ & $40-60$ & 17 \\
\hline A2 & $15-35$ & $20-80$ & $18-27$ & $40-60$ & 21 \\
\hline A3 & $5-40$ & $8-85$ & $18-27$ & $40-60$ & 28 \\
\hline
\end{tabular}

.Table A1 ASHRAE 2015 Thermal Guidelines . 


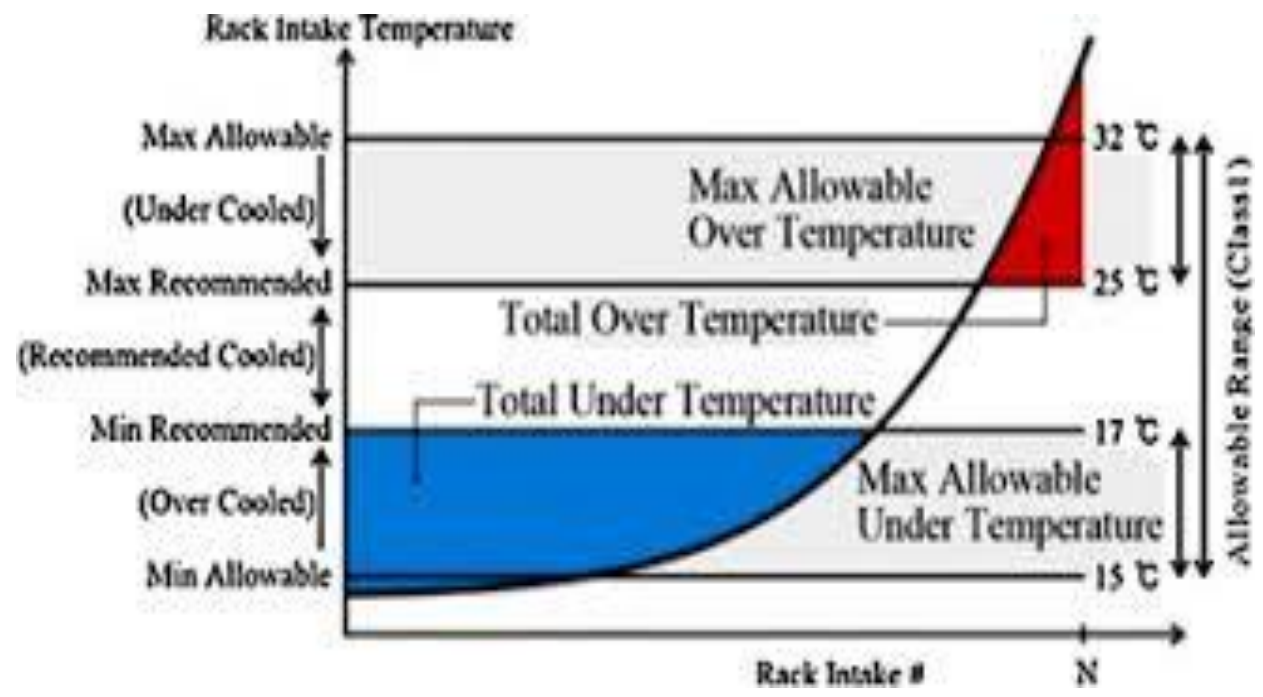

Fig A1 Definition of total over-temperature and total under temperature, [18]

Table A1 indicate for recommend and allowable ranges for temperature and relative humidity as well as in Fig. A2, A3 and A4 The consequence of design change has been an increase in exhaust air temperatures of almost $10^{\circ} \mathrm{C}\left(18^{\circ} \mathrm{F}\right)$ over the last 8 years Fig. $\mathrm{A} 2$, Exhaust temperature rise for air inlet temperatures of $35^{\circ} \mathrm{C}\left(95^{\circ} \mathrm{F}\right)$ and $45^{\circ} \mathrm{C}$ $\left(113^{\circ} \mathrm{F}\right)$ are shown in Fig. A3 and Fig. A4. As the inlet air temperature rises to $35^{\circ} \mathrm{C}$ $\left(95^{\circ} \mathrm{F}\right)$ and $45^{\circ} \mathrm{C}\left(95^{\circ} \mathrm{F}\right)$, most servers reach a maximum exhaust air temperature somewhere between 58 and $60^{\circ} \mathrm{C}\left(140^{\circ} \mathrm{F}\right)$.

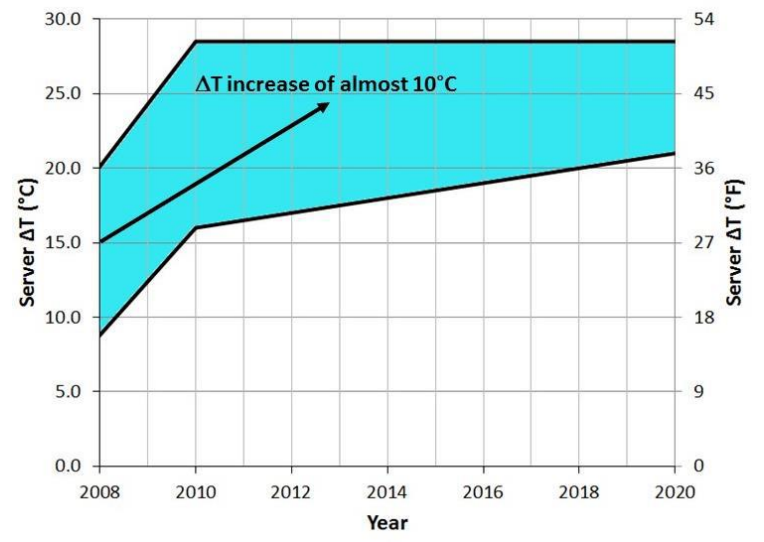

Fig. A2 Server $\Delta \mathrm{T}$ projection at $25^{\circ} \mathrm{C}\left(7^{\circ} \mathrm{F}\right)$ server inlet temperature [19]

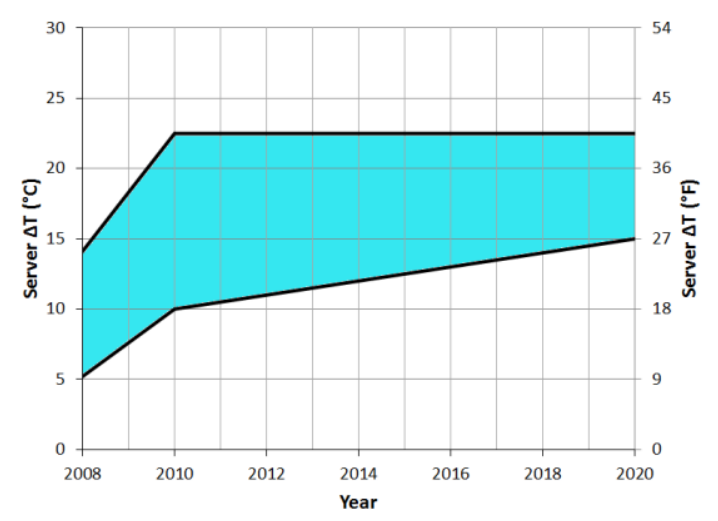

Fig. A3 Server $\Delta \mathrm{T}$ projection at $35^{\circ} \mathrm{C}$ $\left(95^{\circ} \mathrm{F}\right)$ server inlet temperature [19] 
Momtaz Sedrak / Engineering Research Journal 168 (Decamber2020) M1- M29

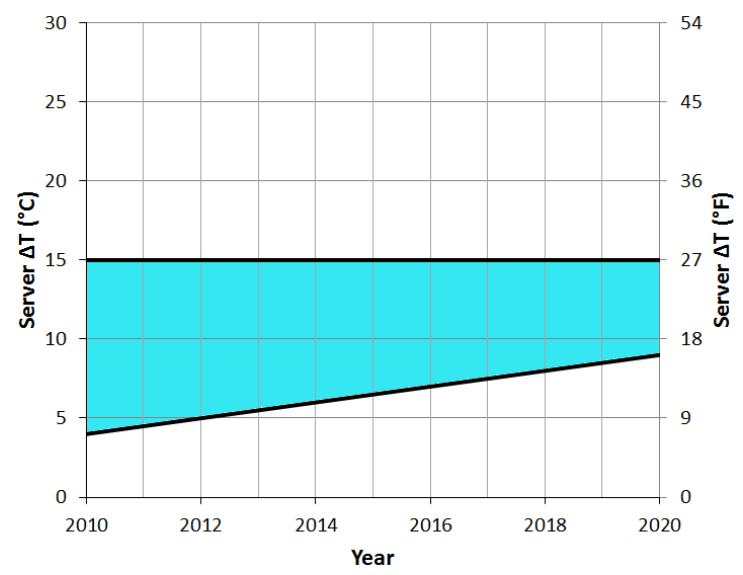

Fig. A4 Server $\Delta \mathrm{T}$ projection at $45^{\circ} \mathrm{C}\left(113^{\circ} \mathrm{F}\right)$ Server inlet temperature [19] 